\title{
STRUCTURE OF THE COMA: CHEMISTRY AND SOLAR WIND INTERACTION
}

\author{
W. F. HUEBNER, D. C. BOICE \\ Southwest Research Institute \\ P. O. Drawer 28510 \\ San Antonio, TX 78228-0510, USA \\ and \\ H. U. SCHMIDT, R. WEGMANN \\ Max-Planck-Institut für Astrophysik \\ Karl-Schwarzschild-Str. 1 \\ D-8046 Garching, FRG
}

\begin{abstract}
Much has been learned about the physics and chemistry of comets from the successful spacecraft encounters and intensive remote observing programs of Comets Halley and GiacobiniZinner. Instead of being the panacea for our comet curiosity, these tantalizing "snapshots" have raised new questions, and many fundamental problems remain unsolved. To reap fuller benefits, extensive modeling is necessary to characterize the physical structure and chemical properties of the coma and to infer the composition and structure of the nucleus.

We review coma science from the bow shock to the nucleus-coma interface and the formation of the plasma tail. Surrounding the nucleus is a collision-dominated inner region with approximate spherical symmetry. Parent molecules leaving the surface are quickly transformed into a plethora of highly reactive radicals and ions by the attenuated solar ultraviolet (UV) flux and a variety of gas-phase reactions. Departures from spherical symmetry caused by nucleus activity, distributed sources, UV flux, and radiation pressure are discussed. At larger distances from the nucleus, species progressively separate into a multifluid ensemble. As a result, the thermal evolution of the neutral species, the production and energetics of the ions and electrons, and the dynamics of nonthermal atomic and molecular hydrogen must be considered. Dust is a distributed source for some coma species and may provide additional clues to the organic inventory of the nucleus.

The solar wind is coupled to the cometary plasma and neutral gases via collisions and the interplanetary magnetic field (IMF). This interaction dramatically affect the plasma flow, resulting in the formation of the plasma tail and discontinuities, such as the bow shock and the contact surface. The Lorentz forces have been modeled in three dimensions with a steady IMF and in the limit of a rapidly changing IMF with averaged effects and detailed chemistry. Counter- and crossstreaming of the ions with respect to the neutrals further affects the plasma flow.

Model results have been compared with observations with varying degrees of success. These results are reviewed to describe the cometary environment and to highlight outstanding problems for planning future cometary missions and research.
\end{abstract}




\section{Introduction}

The third year after the successful missions to Comet Halley is a particularly good time to review the results that have been obtained, since this is the time when the data are becoming available to a larger group of scientific investigators. Our review of coma properties is based on Earth-based observations and in situ measurements, data analysis, and interpretation of the data. Ground-based, airborne, rocket-borne, and Earth satellite observations yield global averages of the coma, while spacecraft in situ measurements yield data on local, instantaneous conditions. Although we do not discuss data analysis, it should be remembered how important it is for obtaining meaningful results by clearly identifying and extracting signals from the noise. Interpretation of the data is always based on a model. We distinguish between two extreme types of models: restricted models and global models. In restricted models, interpretations are made in a limited context, with other evidence, observations, and measurements. Initial interpretations are usually done within the framework of a restricted model. In a global model, interpretations are made to be consistent with all other known information. For example, the physics and chemistry of the coma cannot be treated independently of each other, nor can the coma be treated completely independently of the properties of the nucleus surface or of the solar wind interaction. The more complete a global model is, the more sophisticated it must be. However, only processes viewed in the context of a global model will give a full understanding of the physics and chemistry of the coma.

In a comprehensive, global model, the physics and chemistry of the nucleus surface layer, the gas production, the dust entrainment, the dissociation and ionization of the coma gas, the radiation pressure on the dust and gas species, the solar wind interaction with the coma ions and with the coma neutrals through charge exchange and momentum exchange by elastic collisions, and the plasma and dust tail formation (to mention just a few important processes) are closely interwoven. There is little hope that a global model will ever be able to encompass all of these processes. Restricted global models are a natural consequence of this complexity.

A specific example of processes that have not been included in any global model is the very beautiful synthetic spectrum of the $\mathrm{C}_{2}(0,0)$ Swan bands produced by Gredel et al. (1989) (see Fig. 1). After many decades of dedicated work by many researchers, including Krishna Swamy and O'Dell (1981), the explanation based on restricted models (although they are global to some degree by taking into account the detailed solar flux, a density profile in the coma, detailed molecular calculations, etc.) is so good that a more comprehensive model will not improve them significantly. The reason is that other processes in the environment have very little influence on $\mathrm{C}_{2}$ emissions.

At the other extreme is perhaps the Haser model. It is used to determine the scale length of molecular species in the coma. In spite of its popularity and many improvements to the original model by including radiation pressure and asymmetric gas production (Haser, 1966), its application has not significantly increased our knowledge of mother molecules. Table 1 illustrates the problem in an oversimplified way. Average values are presented of the scale length data of A'Hearn and Cowan (1980), A'Hearn (1982), Combi and Delsemme (1980, 1986), Newburn and Spinrad (1984), Bockelée-Morvan and Crovisier (1985), Cochran (1985), Schloerb et al. (1987), Gammelgaard and Thomson (1988), O'Dell et al. (1988), and Wyckoff et al. (1988). Production of a species depends on the dissociation scale length of a parent, while all processes are considered for the destruction of the daughter. Assuming an outflow speed of about $1 \mathrm{~km} / \mathrm{s}$, only the lifetime of $\mathrm{CN}$ under the conditions of a quiet Sun $\left(v \tau_{\mathrm{QS}}=2.5 \cdot 10^{5} \mathrm{~km}\right)$ agrees reasonably well with the scale length as determined from the Haser model $\left(R_{\text {dest }}=3 \cdot 2 \cdot 10^{5} \mathrm{~km}\right)$. It is possible that some other species can be brought into better agreement once the cross sections from which the lifetimes are calculated are better known. For example, the lifetimes of $\mathrm{C}_{2}$ and $\mathrm{NH}_{2}$ are based only on the dissociation cross section without predissociation. Predissociation could significantly shorten these lifetimes. On the other hand, the lifetime of $\mathrm{CH}$ is already too small, by about a factor of 50 . Similar to the destruction scale lengths, none of the lifetimes seem to fit the production scale lengths. Specifically, it has been pointed out by Wyckoff et al (1988) and Magee-Sauer et al. (1989) that $\mathrm{NH}_{3}$ is not likely the parent 


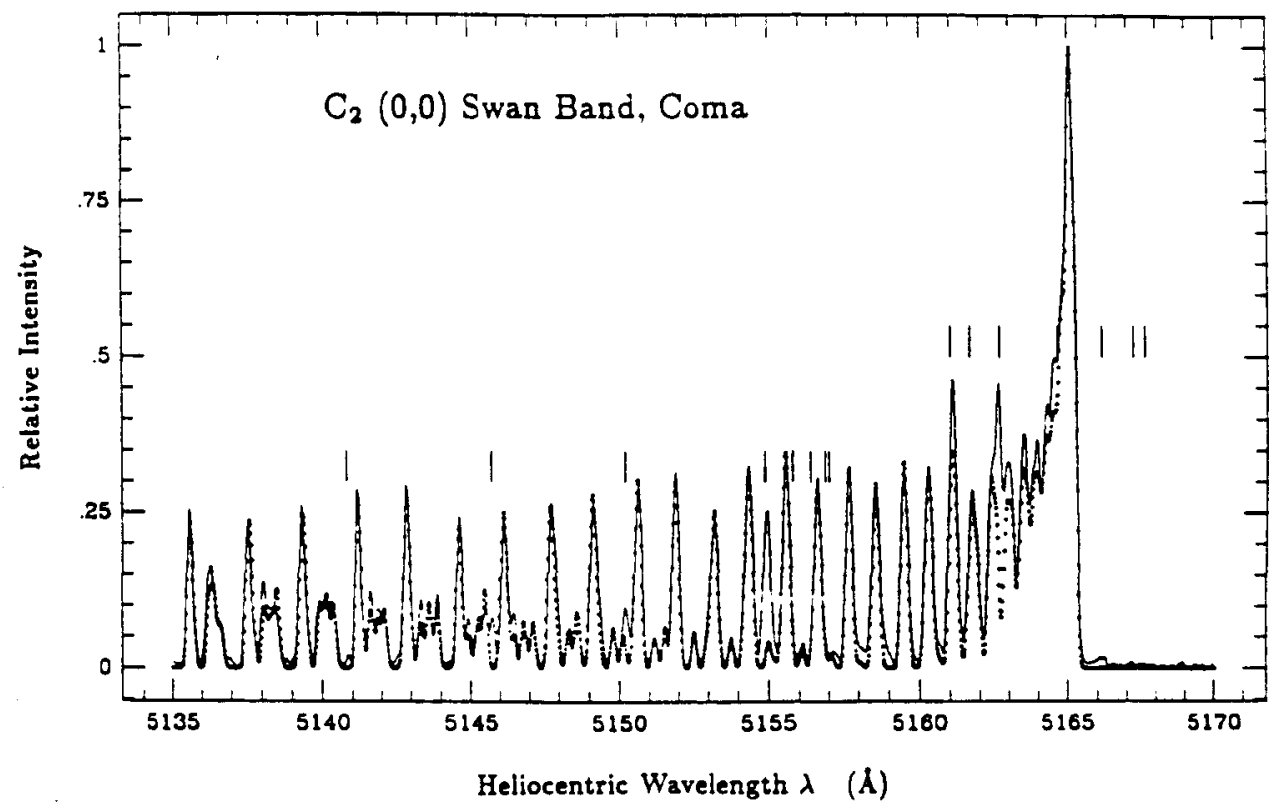

Fig. 1. The observed coma spectrum of the $\mathrm{C}_{2}(0,0)$ Swan band at a resolution of $0.2 \AA$ (solid line). The theoretical spectrum is shown by the dotted line. (Courtesy Gredel et al., 1989.)

of $\mathrm{NH}_{2}$; however, the data have large uncertainties, and it is possible to find a reasonable fit (e.g., see Cochran and Cochran, 1990; Cochran, this volume; Tegler and Wyckoff, 1989). It is possible that other species produce $\mathrm{NH}_{2}$ or that $\mathrm{NH}_{2}$ is produced by chemical reactions or distributed sources from organic dust in the coma. Most likely it is a combination of these processes. The complexity of determining scale lengths based on the Haser model was illustrated recently by Schleicher and Millis (1989), who arrive at a scale length of NH that is 5 to 10 times larger than previously published values by Combi (1978) and Cucchiaro and Malaise (1982).

Table 1. Scale Lengths $(\mathrm{km})$ and Photo Lifetimes (s) at $1 \mathrm{AU}$

\begin{tabular}{llllll}
\hline Species & $R_{\text {prod }}$ & $R_{\text {dest }}$ & $\tau_{\mathrm{QS}}{ }^{1}$ & $\tau_{\mathrm{AS}}{ }^{2}$ & Remarks \\
\hline $\mathrm{CN}$ & $1.8 \cdot 10^{4}$ & $3.2 \cdot 10^{5}$ & $2.5 \cdot 10^{5}$ & $1.1 \cdot 10^{5}$ & $\tau_{\mathrm{HCN}}=7.9 \cdot 10^{4}, \tau_{\mathrm{HC}_{3} \mathrm{~N}}=2.6 \cdot 10^{4}$ \\
$\mathrm{C}_{2}$ & $2.9 \cdot 10^{4}$ & $1.1 \cdot 10^{5}$ & $9.5 \cdot 10^{5}$ & $3.6 \cdot 10^{5}$ & $\tau_{\mathrm{C}_{2} \mathrm{H}_{2}}=3.7 \cdot 10^{5}$ \\
$\mathrm{NH}_{2}$ & $1.1 \cdot 10^{4}$ & $1.6 \cdot 10^{4}$ & $9.7 \cdot 10^{5}$ & $2.7 \cdot 10^{5}$ & $\tau_{\mathrm{NH}_{3}}=5.9 \cdot 10^{3}$ \\
$\mathrm{CH}$ & $1.2 \cdot 10^{4}$ & $6.0 \cdot 10^{3}$ & $1.1 \cdot 10^{2}$ & $1.1 \cdot 10^{2}$ & $\tau_{\mathrm{CH}_{4}}=1.6 \cdot 10^{6}$ \\
\hline
\end{tabular}

${ }^{1} \tau_{\mathrm{QS}}$ is the lifetime for the quiet Sun.

${ }^{2} \tau_{A S}$ is the lifetime for the active Sun. 


\section{The Observed Physical Properties and Chemical Species in the Coma}

\subsection{PHYSICAL PROPERTIES}

Many interesting features of Comet Halley were determined from the spacecraft encounters and ground-based and near-Earth observations. The gas production was seen to be asymmetric, arising from isolated active regions occupying only a small percentage of the total surface. This was confirmed by ground-based observations of gas "jets" of several species (A'Hearn et al., 1986; Cosmovici et al., 1988; Clairemidi et al., 1990) and the Halley Multicolour Camera images showing dust "jets" in the near-nucleus region that act as tracers of the gas dynamics. The bulk of the neutral gas readily isotropizes into a nearly spherical distribution that becomes distorted, at distances greater than a few hundred thousand kilometers from the nucleus, by radiation pressure. The spatial distribution of the ions beyond a few thousand kilometers from the nucleus is greatly influenced by the interaction with the solar wind as the ions are swept away from the Sun to form the plasma tail. Evidence for cometary ion pick-up by the solar wind was observed (Neugebauer et al., 1987), as well as for many other plasma microprocesses (e.g., Galeev, 1987). Hydrogen Lyman- $\alpha$ observations reflect the bimodel spherical distribution of suprathermal $\mathrm{H}$ at velocities of about 9 and $20 \mathrm{~km} / \mathrm{s}$ (Keller, 1976) distorted by radiation pressure. The presence of suprathermal dissociation products of $\mathrm{H}_{2}$ has been inferred by models. The flow of the gas throughout most of the coma is supersonic in the range of 1 to $2 \mathrm{~km} / \mathrm{s}$, as confirmed by the neutral mass spectrometer (NMS) aboard Giotto. The ion velocity was observed to decrease dramatically from solar wind values of 300 to $400 \mathrm{~km} / \mathrm{s}$ to 1 to $2 \mathrm{~km} / \mathrm{s}$ as cometary ions mass-loaded the solar wind flow.

The production rates determined from ground-based observations and measured by the spacecraft were in good agreement at $6 \cdot 10^{29}$ to $7 \cdot 10^{29}$ molecules $\mathrm{s}^{-1}$ during the Giotto encounter. The number density of the neutrals followed very closely an inverse squared distance $\left(R^{-2}\right)$ relation from the nucleus (Gringauz et al., 1986; Krankowsky et al., 1986). The total ion number density decreased with an $R^{-1}$ dependence inside the contact surface and steepened to the $R^{-2}$ relation outside (Balsiger et al., 1986). Upper limits of the gas temperature of the neutrals were measured by the NMS and found to be consistent with theoretical calculations of the energy balance, with most of the cooling caused by a nearly adiabatic expansion of the gas in the inner coma and subsequent heating caused by photo processes. The electron temperature profile displays an enhancement before crossing the bow shock (foreshock), a region of fluctuation interior to the bow shock, and a general cooling towards the nucleus as inelastic collisions with water become more frequent (Rème et al., 1987). The ion temperature profile displays a similar behavior (Coates et al., 1987); however, an unexpected high-energy component of the ion distribution function was detected interior to the contact surface (R. Goldstein et al., 1987).

The Giotto magnetometer recorded the crossing of several boundaries and regions during encounter. The data dramatically demonstrated the draping of the interplanetary magnetic field lines around the comet, which created the pile-up region. The concept of a magnetic field-free cavity interior to the contact surface is consistent with the measurements (Neubauer et al., 1986).

Other boundaries and regions were identified. The Giotto spacecraft crossed the contact surface on the inbound phase of its encounter, penetrating the magnetic field-free cavity. Indirect evidence supports the existence of an inner shock that is so narrow that Giotto may have missed it because of its high speed (Cravens, 1989). The bow shock was crossed by the Suisei and the VEGA 1 and 2 spacecraft, and a region of plasma turbulence, characterized by ion and electron number density and temperature fluctuations, was encountered interior to the bow shock. The cometopause, a previously unknown region of enhanced ion number density but depleted solar wind ions, was discovered to exist between the bow shock and contact surface (Gringauz et al., 1986). 


\subsection{CHEMICAL SPECIES}

All global models of the coma start with a source for the mother molecules of the observed or suspected species. Table 2 lists species that have been identified. Question marks in the table label those species whose identification by their electromagnetic spectrum is not fully verified. In addition, there are the metals $\mathrm{Na}, \mathrm{K}, \mathrm{Ca}, \mathrm{V}, \mathrm{Mn}, \mathrm{Cr}, \mathrm{Fe}, \mathrm{Co}, \mathrm{Ni}$, and $\mathrm{Cu}$ that are clearly associated with the dust seen mostly in Sun-grazing comets. Mass spectrometer identifications are somewhat problematic because of the overlap of masses from different species. A peak in mass channel 16 can be caused by $\mathrm{O}, \mathrm{CH}_{4}$, and $\mathrm{NH}_{2}$, with lesser contributions from some isotopes. Similarly, mass channel 28 contains $\mathrm{CO}, \mathrm{N}_{2}$, and $\mathrm{C}_{2} \mathrm{H}_{4}$ as possible main constituents. There are similar problems with other mass channels. Although $\mathrm{H}_{2} \mathrm{O}$ is so abundant that most of it must come from the nucleus, it is not known what fraction of it and the other species come from spatially extended sources in the coma. Such sources are most likely associated with dust. Relative abundances of observed species have been published by Moroz et al. (1987) and others. Delsemme (this volume) lists the atomic abundances and chemical composition of the nucleus and the dust as deduced from observations and in situ data from $\mathrm{P} / \mathrm{Halley}$. He compares the mean abundances of the light elements in some bright comets with those in $\mathrm{P} / \mathrm{Halley}$. Independent, but more limited, compilations of such data have also been published by Encrenaz et al. (1988) and Geiss (1988).

Table 2. Species Identified in Comets

Identification by radio, IR, visual, and UV spectra:

$\mathrm{H}, \mathrm{C}, \mathrm{O}, \mathrm{S}, \mathrm{C}_{2},{ }^{12} \mathrm{C}^{13} \mathrm{C}, \mathrm{CH}, \mathrm{CN},{ }^{13} \mathrm{CN}, \mathrm{CO}, \mathrm{CS}, \mathrm{NH}, \mathrm{OH}, \mathrm{S}_{2}, \mathrm{SH}$ ?, SO?, NO?, $\mathrm{C}_{3}, \mathrm{NH}_{2}, \mathrm{H}_{2} \mathrm{O}$, $\mathrm{HCN}, \mathrm{HCO}, \mathrm{H}_{2} \mathrm{~S}$ ?, $\mathrm{NH}_{3}, \mathrm{H}_{2} \mathrm{CO}, \mathrm{CH}_{3} \mathrm{CN}, \mathrm{CH}_{3} \mathrm{OH}$ ? $\mathrm{C}^{+}, \mathrm{CO}^{+}, \mathrm{CH}^{+}, \mathrm{CN}^{+}, \mathrm{N}_{2}^{+}, \mathrm{NH}_{4}^{+}, \mathrm{OH}^{+}$, $\mathrm{CO}_{2}^{+}, \mathrm{H}_{2} \mathrm{O}^{+}, \mathrm{SH}^{+}$

Identification by mass spectra:

$\mathrm{H}_{2} \mathrm{O}, \mathrm{CO} / \mathrm{N}_{2} / \mathrm{C}_{2} \mathrm{H}_{4}, \mathrm{CO}_{2}, \mathrm{H}_{2} \mathrm{CO}, \mathrm{H}^{+}, \mathrm{C}^{+}, \mathrm{CH}^{+}, \mathrm{CH}_{2}^{+} / \mathrm{N}^{+}, \mathrm{CH}_{3}^{+} / \mathrm{NH}^{+}, \mathrm{O}^{+} / \mathrm{CH}_{4}^{+} / \mathrm{NH}_{2}^{+}$, $\mathrm{OH}^{+} / \mathrm{NH}_{3}^{+} / \mathrm{CH}_{5}^{+}, \mathrm{H}_{2} \mathrm{O}^{+} / \mathrm{NH}_{4}^{+}, \mathrm{H}_{3} \mathrm{O}^{+}, \mathrm{H}_{3} \mathrm{~S}^{+}, \mathrm{C}_{3} \mathrm{H}_{3}^{+}, \mathrm{C}_{3} \mathrm{H}^{+}$

\section{The Collision-Dominated Inner Coma Models}

\subsection{SPHERICAL SYMMETRY}

3.1.1. Physics. For heliocentric distances $r<1.5 \mathrm{AU}$, the gas production rate for active and moderately active comets varies as $1 / r^{2}$. For these comets, the specific gas production rate is $Z=10^{17}$ to $10^{18}$ molecules $\mathrm{cm}^{-2} \mathrm{~s}^{-1}$ at $1 \mathrm{AU}$, and the surface temperature is about $200 \mathrm{~K}$. The gas-flow away from the surface is one-fourth of the speed of sound, which is about $3 \cdot 10^{4} \mathrm{~cm} / \mathrm{s}$. The resulting gas density is $n_{\mathrm{N}}=Z / v_{\mathrm{N}}=10^{13}$ to $10^{14} \mathrm{~cm}^{-3}$. The mean free path for molecular collisions is $A\left(R_{\mathrm{N}}\right)=1 /\left(\sqrt{2} n_{\mathrm{N}} \sigma\right) \simeq 10 \mathrm{~cm}$ at the nucleus, assuming a collisional cross section of $\sigma \simeq 10^{-15} \mathrm{~cm}^{2}$. The gas density at a cometocentric distance $R$ in the coma is

$$
n(R)=n_{\mathrm{N}} \frac{v_{\mathrm{N}} R_{\mathrm{N}}^{2}}{v R^{2}},
$$

for $R$ much less than the range of the gas species, i.e., ignoring photolysis. The internal energy that a molecule carries when it is evaporated at the nucleus is converted to translational energy. At a distance of $R=10^{3} R_{\mathrm{N}}$, the velocity has increased to 3 to 4 times the value at the mucleus. The size of the collision-dominated inner coma can be defined as the volume inside of which the mean free 
path is less than the characteristic radius defining the volume, i.e., $R_{c}=R(\Lambda=R)$. From the above values, $R_{\mathrm{c}}=\Lambda_{\mathrm{c}} \simeq 3 \cdot 10^{3} \mathrm{~km}$, where $\Lambda_{\mathrm{c}}$ is the value of $A$ at $R=R_{\mathrm{c}}$.

Since the inner coma is collision-dominated, coma models are usually based on hydrodynamic calculations. Some of these consider the nucleus-coma interface in detail (Crifo, 1987), others consider gas and dust interaction (Marconi and Mendis, 1982; Körösmezey and Gombosi, 1990; Kitamura, 1986, 1987; Kömle and Ip 1987), while still others consider the chemistry in greater detail (Allen et al. 1987; Huebner, 1985), and finally there is a group that considers the coma-solar wind interaction (Mendis et al., 1984; Wegmann et al. 1987; Schmidt et al., 1988). The outer coma is a dilute gas with a density so low that collisions are rare and fluid dynamics is not justified. This region will be discussed in Sect. 4.1.

Some coma models give good agreement with in situ spacecraft measurements. For example, coma outflow velocities of neutral gas were measured in $\mathrm{P} / \mathrm{Halley}$ by the Giotto Neutral Mass Spectrometer (NMS) by Lämmerzahl et al. (1987) (see Fig. 2). Beyond about $2000 \mathrm{~km}$, these velocities show a monotonic increase out to about $40,000 \mathrm{~km}$. At that distance, the velocity is 1.1 $\mathrm{km} / \mathrm{s}$ and still rising. The models of Schmidt et al. (1988) and Combi (1989) indicate a velocity of about $1.2 \mathrm{~km} / \mathrm{s}$ at that distance (see Figs. 3 and 4). Final velocities approaching $1.6 \mathrm{~km} / \mathrm{s}$ at distances beyond $10^{5} \mathrm{~km}$ are given by Schmidt et al. (1988). These authors also predict that monatomic species dominate over diatomic and polyatomic species beyond about $10^{5} \mathrm{~km}$ (see Fig. 5).

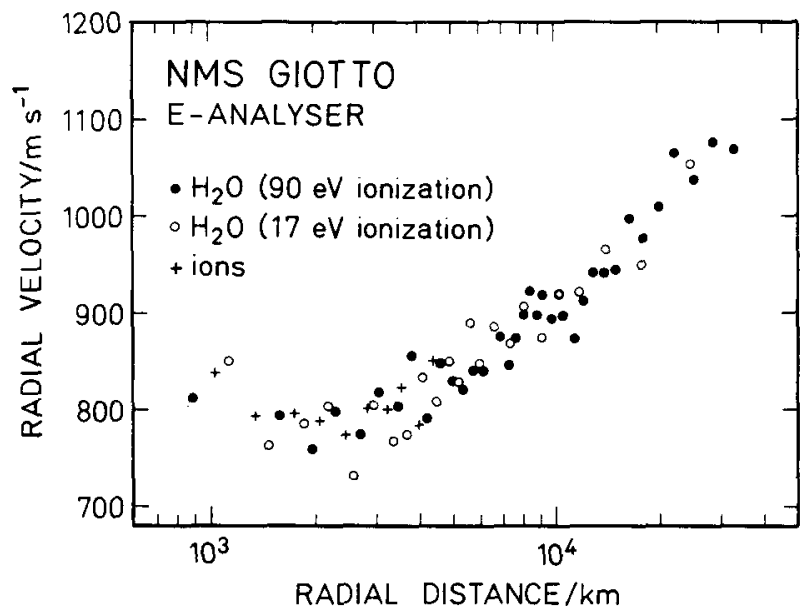

Fig. 2. Coma outflow velocities as observed from ram energies of water molecules (using two different electron energies for ionization) and of ion spectra (inside the contact surface only). (Courtesy Lämmerzahl et al., 1987.)

3.1.2. Chemistry. In Table 3, we represent the chemical reactions for the inner coma. The reactions are listed in decreasing order of importance. For example, dissociation, especially of water, occurs everywhere in the coma, with the possible exception of the first hundred kilometers above the nucleus, where the coma is optically thick in the UV. Since the detection of sulfur species is relatively new, we present a reaction diagram for sulfur-bearing species based on $\mathrm{CS}_{2}$, the suspected mother molecule (see Fig. 6). 


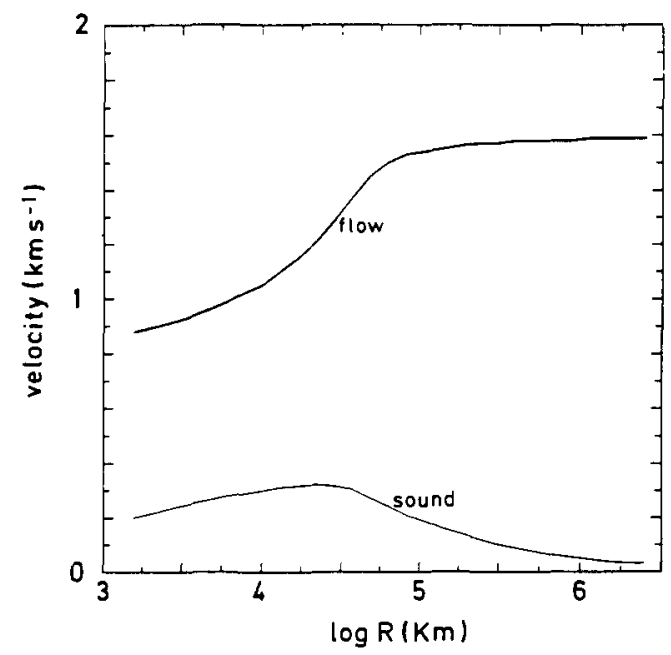

Fig. 3. Model calculation of sound speed and outflow speed of neutrals. (Courtesy Schmidt et al., 1988.)

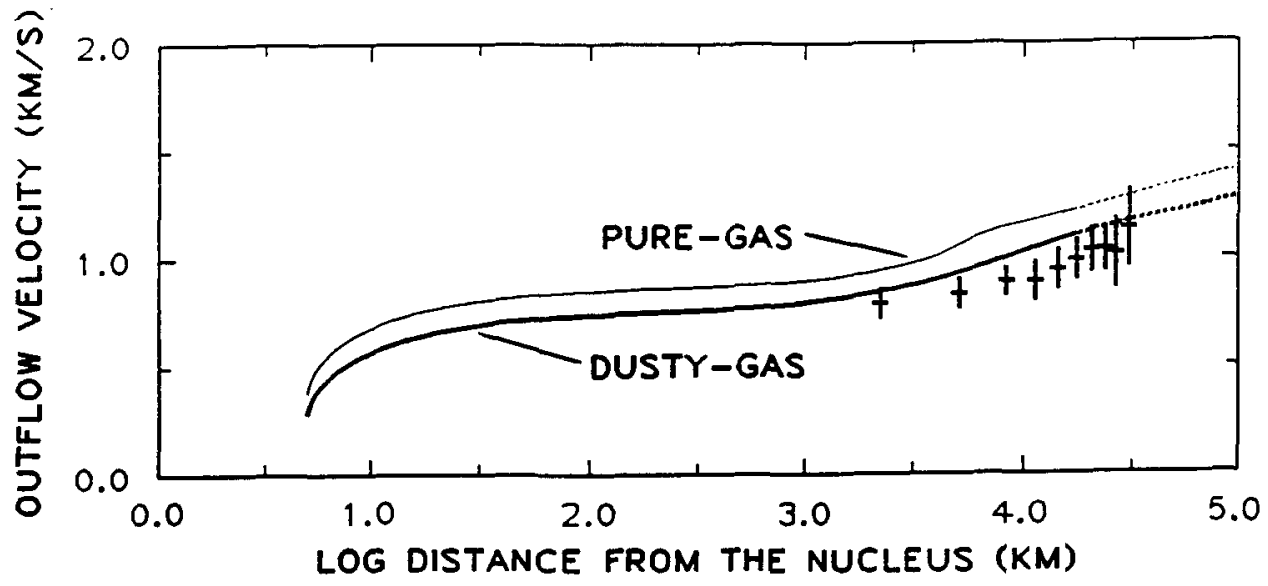

Fig. 4. Outflow speeds for pure gas and dusty gas from model calculations. (Courtesy Combi, 1989.) 


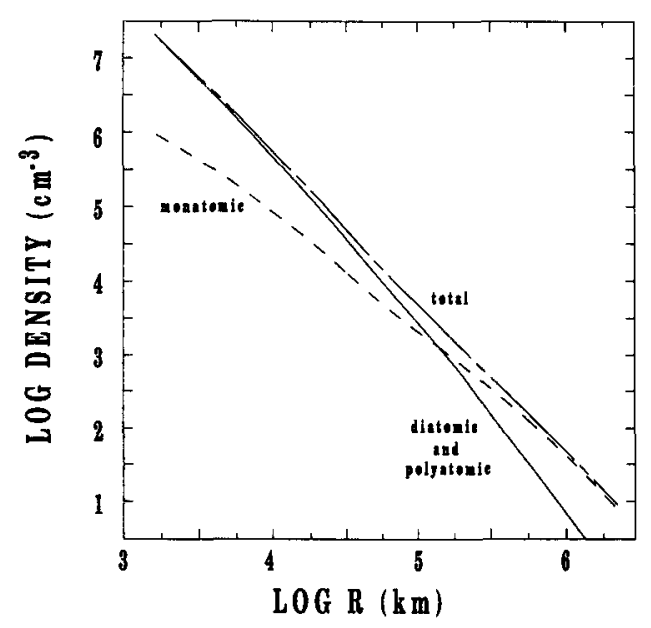

Fig. 5. The density of neutrals from model calculations. (Courtesy Schmidt et al., 1988.)

Table 3. Gas-Phase Chemical Reactions With Examples

\begin{tabular}{ll}
\hline Photodissociation & $h \nu+\mathrm{H}_{2} \mathrm{O} \rightarrow \mathrm{H}+\mathrm{OH}$ \\
Photoionization & $h \nu+\mathrm{CO} \rightarrow \mathrm{CO}+\mathrm{e}$ \\
Photodissociative ionization & $h \nu+\mathrm{CO}_{2} \rightarrow \mathrm{O}+\mathrm{CO}^{+}+\mathrm{e}$ \\
Electron impact dissociation & $\mathrm{e}+\mathrm{N}_{2} \rightarrow \mathrm{N}+\mathrm{N}+\mathrm{e}$ \\
Electron impact ionization & $\mathrm{e}+\mathrm{CO} \rightarrow \mathrm{CO}+\mathrm{e}+\mathrm{e}$ \\
Electron impact dissociative ionization & $\mathrm{e}+\mathrm{CO}_{2} \rightarrow \mathrm{O}+\mathrm{CO}^{+}+\mathrm{e}+\mathrm{e}$ \\
Positive ion-atom interchange & $\mathrm{CO}^{+}+\mathrm{H}_{2} \mathrm{O} \rightarrow \mathrm{HCO}^{+}+\mathrm{OH}$ \\
Positive ion charge transfer & $\mathrm{CO}^{+}+\mathrm{H}_{2} \mathrm{O} \rightarrow \mathrm{H}_{2} \mathrm{O}^{+}+\mathrm{CO}$ \\
Electron dissociative recombination & $\mathrm{C}_{2} \mathrm{H}^{+}+\mathrm{e} \rightarrow \mathrm{C}_{2}+\mathrm{H}$ \\
Three-body positive ion-neutral association & $\mathrm{C}_{2} \mathrm{H}_{2}^{+}+\mathrm{H}_{2}+\mathrm{M} \rightarrow \mathrm{C}_{2} \mathrm{H}_{4}^{+}+\mathrm{M}$ \\
Neutral rearrangement & $\mathrm{N}+\mathrm{CH} \rightarrow \mathrm{CN}+\mathrm{H}$ \\
Three-body neutral recombination & $\mathrm{C}_{2} \mathrm{H}_{2}+\mathrm{H}+\mathrm{M} \rightarrow \mathrm{C}_{2} \mathrm{H}_{3}+\mathrm{M}$ \\
Radiative electronic state deexcitation & $\mathrm{O}\left({ }^{1} \mathrm{D}\right) \rightarrow \mathrm{O}\left({ }^{3} \mathrm{P}\right)+h \nu$ \\
Radiative recombination & $\mathrm{e}+\mathrm{H}^{+} \rightarrow \mathrm{H}+h \nu$ \\
Radiation stabilized positive ion-neutral association & $\mathrm{C}+\mathrm{H} \rightarrow \mathrm{CH}+\mathrm{H}^{+}+h \nu$ \\
Radiation stabilized neutral recombination & $\mathrm{C}+\mathrm{C} \rightarrow \mathrm{C}_{2}+h \nu$ \\
Neutral-neutral associative ionization & $\mathrm{CH}+\mathrm{O} \rightarrow \mathrm{HCO}+\mathrm{e}$ \\
Neutral impact electronic state quenching & $\mathrm{O}\left({ }^{1} \mathrm{D}\right)+\mathrm{CO}{ }_{2} \rightarrow \mathrm{O}\left({ }^{3} \mathrm{P}\right)+\mathrm{CO}$ \\
Electron impact electronic state excitation & $\mathrm{CO}\left({ }^{1} \Sigma\right)+\mathrm{e} \rightarrow \mathrm{CO}\left({ }^{1} \Pi\right)+\mathrm{e}$ \\
\hline
\end{tabular}

The molecule $\mathrm{S}_{2}$ was detected by A'Hearn et al. (1983) in the coma of Comet IRAS-ArakiAlcock. It has not been found in any other comet since then. Its presence in comets is poorly understood, and it contributes to coma chemistry only through its destruction. We have therefore not included it in Fig. 6 .

Just as dissociation products increase with distance from the nucleus, so do ionization products. In the inner coma, ions are never more abundant than a few percent. However, even there, ions play an important role, since they cannot cross the contact surface. Ions born inside the contact surface - primarily by photoionization and secondary photoelectron collisional ionization $\neg$ respond to the 
solar wind pressure from the outside, are slowed down, and increasingly recombine dissociatively with electrons. Since atomic ions can only recombine radiatively, by three-body recombination, or by dielectronic recombination (both of these cross sections are smaller than that of dissociative recombination of molecular ions), the ions tend to be deflected, together with a few molecular ions, into the tail. Outside the contact surface, ions are created by photoionization and charge exchange with the solar wind protons. Since these ions (primarily $\mathrm{H}_{2} \mathrm{O}^{+}$) are much heavier than the solar wind ions (mostly $\mathrm{H}^{+}$), they mass-load the solar wind and decelerate it. As the ions approach the contact surface from the outside, they are slowed down, pile up, and recombine or are deflected into the plasma tail, consisting primarily of ions that originate from outside the contact surface.

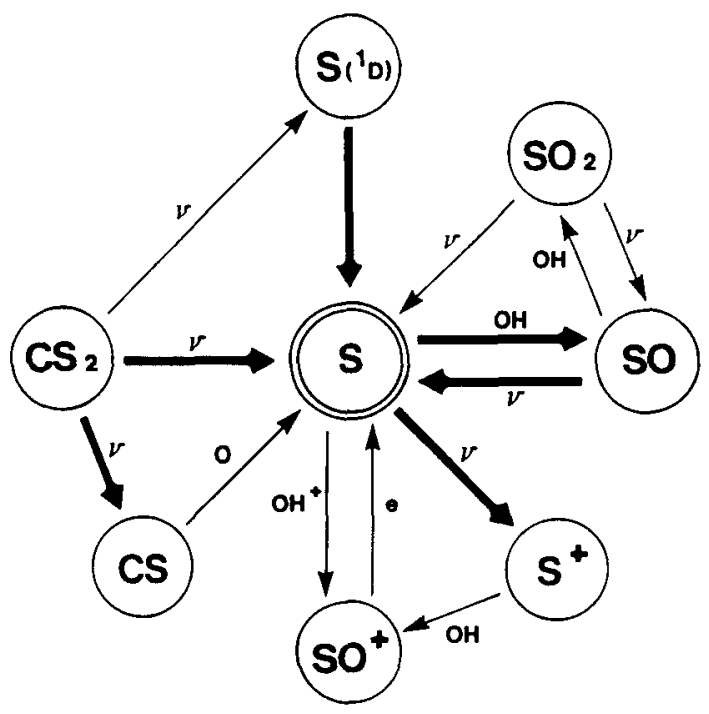

Fig. 6. Major sulfur reactions at a cometocentric distance of $R=1500 \mathrm{~km}$, assuming $\mathrm{CS}_{2}$ as the mother molecule. Symbols next to the arrows indicate the reactants; $\nu$ indicates photodissociation or photoionization. (Courtesy Wegmann et al., 1987.)

Ions are easily detected by mass spectrometers, and these ions play a dominant role in the chemistry through ion-neutral reactions. Figure 7 illustrates the creation and destruction of some of the most important ions. It should be noted that $\mathrm{H}_{3} \mathrm{O}^{+}, \mathrm{NH}_{4}^{+}$, and $\mathrm{CH}_{2} \mathrm{OH}^{+}$cannot be created by photoionization of mother molecules in the nucleus; they are protonated species $\mathrm{of}_{2} \mathrm{O}, \mathrm{NH}_{3}$, and $\mathrm{H}_{2} \mathrm{CO}$. Heavy arrows indicate the major production and destruction paths. Solid lines indicate paths of intermediate strength, with rate coefficients about a factor of ten lower than those of the major reactions. Dashed lines indicate reactions with a further reduction by a factor of ten. These reaction paths are typical for comets at a heliocentric distance of $1 \mathrm{AU}$ and a cometocentric distance of approximately $1600 \mathrm{~km}$ in the coma. Figure 8 links many of these reactions and relates them to other species. The relative importance of these reactions changes with heliocentric and cometocentric distances (Huebner et al., 1982). The reaction rates can be found in Schmidt et al. (1988).

In Table 4, we summarize the major ion species and some secondary ones as they might be detected in an ion mass spectrometer (IMS). All of the ions shown were included in the chemical reaction network of Schmidt et al. (1988). We call particular attention to the mass channels 39, 45, 

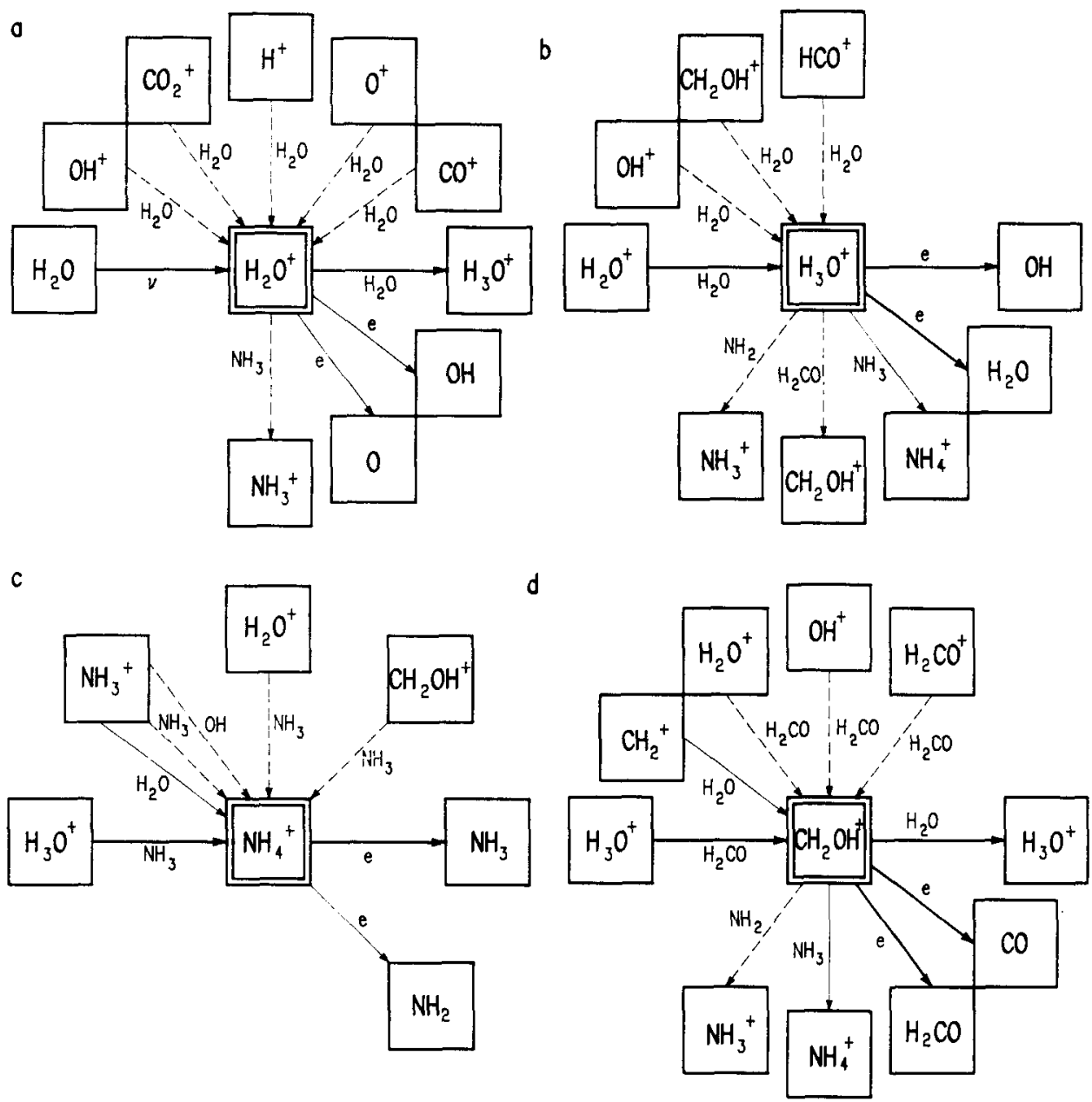

Fig. 7. Major reactions to form: (a) $\mathrm{H}_{2} \mathrm{O}^{+}$, (b) $\mathrm{H}_{3} \mathrm{O}^{+}$, (c) $\mathrm{NH}_{4}^{+}$, and (d) $\mathrm{CH}_{2} \mathrm{OH}^{+}$. Symbols next to the arrows indicate the reactants, $\nu$ indicates photodissociation or photoionization, and e indicates electron dissociative recombination.

and 47; these correspond to $\mathrm{C}_{3} \mathrm{H}_{3}^{+}, \mathrm{HCS}^{+}$and $\mathrm{HCO}_{2}^{+}$, and $\mathrm{H}_{3} \mathrm{CS}^{+}$and $\mathrm{HNS}^{+}$, respectively. These channels show local peaks in IMS instruments aboard Giotto. Figure 9 shows part of the spectrum of the Positive Ion Cluster Composition Analyser (PICCA). The cyclic ion of cyclopropenyl $(\mathrm{M} / q=$ $39 \mathrm{amu} / \mathrm{e}$ ), corresponding to $\mathrm{C}_{3} \mathrm{H}_{3}^{+}$in Table 4, was identified by Korth et al. (1989). They argue that cyclopropenyl (see Fig. 10) must be released by the dust as a distributed source in the coma. While we do not disagree with this scenario, we note alternatively that $\mathrm{C}_{3} \mathrm{H}_{3}^{+}$can be created in sufficient quantities from a small amount $(0.1 \%)$ of the potential mother molecule $\mathrm{H}_{2} \mathrm{C}_{3} \mathrm{H}_{2}$ (allene). Consideration of the radiative association reaction $\mathrm{C}_{3} \mathrm{H}^{+}+\mathrm{H}_{2} \rightarrow \mathrm{C}_{3} \mathrm{H}_{3}^{+}$(Herbst, 1987), previously not included in our reaction network, could lower the required nucleus abundance of $\mathrm{H}_{2} \mathrm{C}_{3} \mathrm{C}_{2}$ even further. 


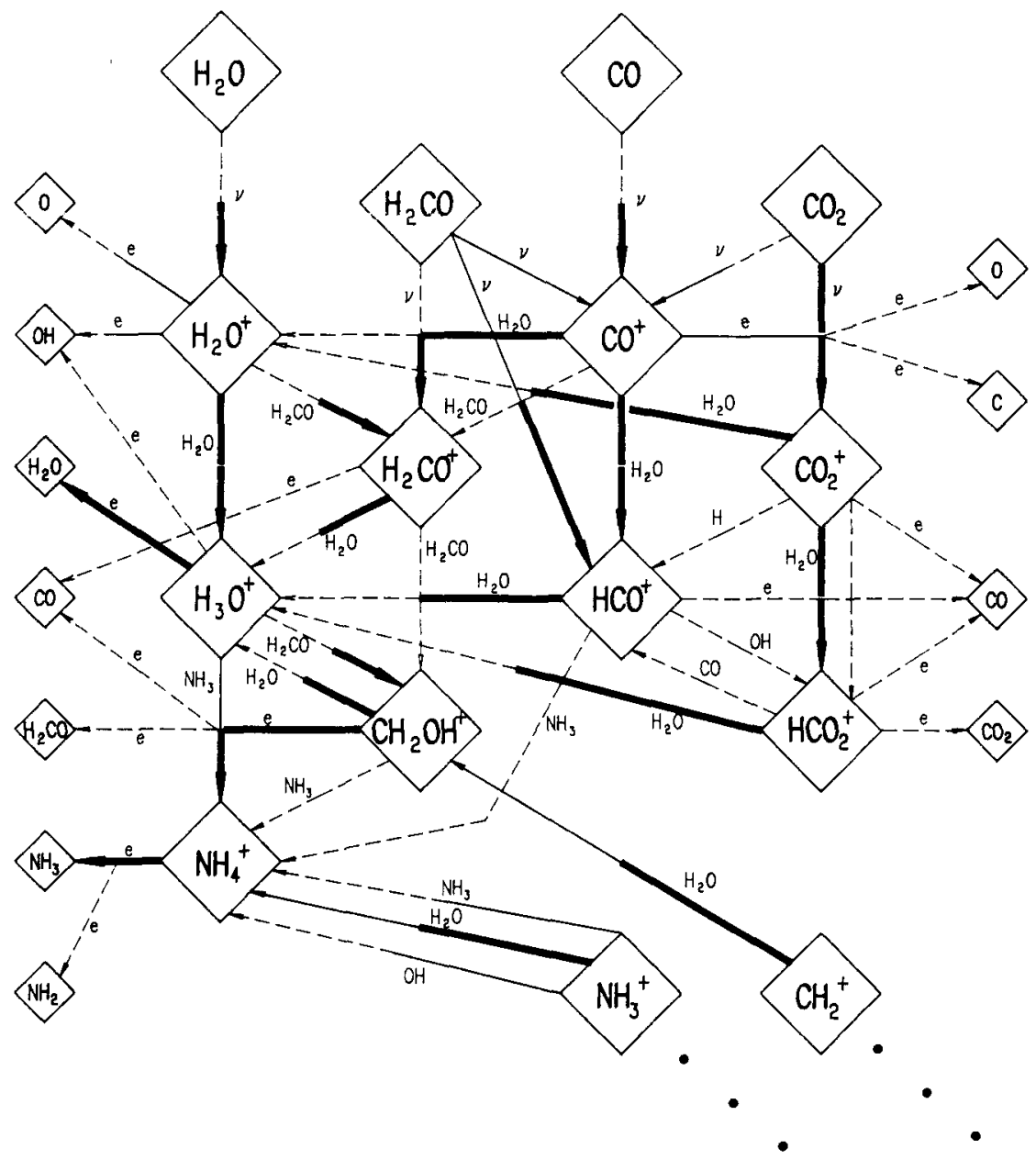

Fig. 8. Relationship of the reactions of Fig. 7. Symbols have the same meaning as in Fig. 7 .

\subsection{ASYMMETRIES}

Jet-like dust features had been detected in many comets, but jet-like structures in the coma gas were first identified in P/Halley (Millis and Schleicher, 1986; A'Hearn et al., 1986; Cosmovici et al. 1988). The origin of these structures is not fully understood. They do not appear to be correlated with the observed dust features. However, very small dust grains had been detected by in situ measurements in $\mathrm{P} / \mathrm{Halley}$ in large abundances. It is possible that the gas structures are related to dust "jets" of organic (CHON) particles that are so small that they do not scatter sunlight, but are large enough that surface winds do not significantly accelerate them in a transverse direction. These CHON particles may disintegrate and release species that are the source of the observed "jets" of $\mathrm{CN}, \mathrm{C}_{2}$, etc. 
Table 4. Dominant Ions in Mass/Charge Bins

\begin{tabular}{llll}
\hline$M / q$ & Ion Species & $M / q$ & Ion Species \\
\hline 12 & $\mathrm{C}^{+}$ & 34 & ${ }^{34} \mathrm{~S}^{+}, \mathrm{H}_{2} \mathrm{~S}^{+}$ \\
13 & $\mathrm{CH}^{+},{ }^{13} \mathrm{C}^{+}$ & 35 & $\mathrm{H}_{3} \mathrm{~S}^{+}$ \\
14 & $\mathrm{CH}_{2}^{+}, \mathrm{N}^{+}$ & 36 & $\mathrm{C}_{3}^{+}$ \\
15 & $\mathrm{CH}_{3}^{+}, \mathrm{NH}^{+}$ & 37 & $\mathrm{C}_{3} \mathrm{H}^{+}, \mathrm{H}_{3} \mathrm{O}^{+} \cdot \mathrm{H}_{2} \mathrm{O}$ \\
16 & $\mathrm{O}^{+}, \mathrm{CH}_{4}^{+}, \mathrm{NH}_{2}^{+}$ & 38 & $\mathrm{C}_{2} \mathrm{~N}^{+}, \mathrm{C}_{3} \mathrm{H}_{2}^{+}$ \\
17 & $\mathrm{OH}^{+}, \mathrm{NH}_{3}^{+}, \mathrm{CH}_{5}^{+}$ & 39 & $\mathrm{C}_{3} \mathrm{H}_{3}^{+}$ \\
18 & $\mathrm{H}_{2} \mathrm{O}^{+}, \mathrm{NH}_{4}^{+}$ & 40 & $\mathrm{C}_{3} \mathrm{H}_{4}^{+}, \mathrm{CH}_{2} \mathrm{CN}^{+}$ \\
19 & $\mathrm{H}_{3} \mathrm{O}^{+}$ & 41 & $\mathrm{C}_{3} \mathrm{H}_{5}^{+}$ \\
20 & $\mathrm{H}_{2}{ }^{18} \mathrm{O}^{+}$ & 42 & - \\
21 & $\mathrm{H}_{3}{ }^{18} \mathrm{O}^{+}$ & 43 & $\mathrm{CH}_{3} \mathrm{CO}^{+}$ \\
22 & - & 44 & $\mathrm{CO}_{2}^{+}, \mathrm{CS}^{+}, \mathrm{C}_{3} \mathrm{H}_{8}^{+}$ \\
23 & - & 45 & $\mathrm{HCS}^{+}, \mathrm{HCO}_{2}^{+}$ \\
24 & $\mathrm{C}_{2}^{+}$ & 46 & $\mathrm{H}_{2} \mathrm{CO}_{2}^{+}, \mathrm{NS}^{+}, \mathrm{H}_{2} \mathrm{CS}^{+}$ \\
25 & $\mathrm{C}_{2} \mathrm{H}^{+}$ & 47 & $\mathrm{H}_{3} \mathrm{CS}^{+}, \mathrm{HNS}^{+}$ \\
26 & $\mathrm{C}_{2} \mathrm{H}_{2}^{+}, \mathrm{CN}^{+}$ & 48 & $\mathrm{SO}^{+}$ \\
27 & $\mathrm{C}_{2} \mathrm{H}_{3}^{+}, \mathrm{HCN}^{+}$ & 49 & $\mathrm{HSO}^{+}$ \\
28 & $\mathrm{H}_{2} \mathrm{CN}^{+}, \mathrm{CO}^{+}, \mathrm{N}_{2}^{+}, \mathrm{C}_{2} \mathrm{H}_{4}^{+}$ & 50 & $\mathrm{C}_{4} \mathrm{H}_{2}^{+}$ \\
29 & $\mathrm{HCO}^{+}, \mathrm{C}_{2} \mathrm{H}_{5}^{+}, \mathrm{N}_{2} \mathrm{H}^{+}$ & 51 & $\mathrm{C}_{4} \mathrm{H}_{3}^{+}$ \\
30 & $\mathrm{H}_{2} \mathrm{CO}^{+}, \mathrm{CH}_{4} \mathrm{~N}^{+}, \mathrm{NO}^{+}, \mathrm{C}_{2} \mathrm{H}_{6}^{+}$ & 52 & $\mathrm{C}_{3} \mathrm{H}_{2} \mathrm{~N}^{+}$ \\
31 & $\mathrm{CH}_{2} \mathrm{OH}^{+}, \mathrm{HNO}^{+}$ & 53 & $\mathrm{C}_{4} \mathrm{H}_{5}^{+}$ \\
32 & $\mathrm{~S}^{+}, \mathrm{O}_{2}^{+}$ & - \\
33 & $\mathrm{HS}^{+}, \mathrm{O}_{2} \mathrm{H}^{+}$ & 54 & $\mathrm{C}_{3} \mathrm{H}_{3} \mathrm{O}^{+}, \mathrm{C}_{4} \mathrm{H}_{7}^{+}$ \\
\hline
\end{tabular}

3.2.1. Nucleus Activity. The nucleus is known to be irregular in shape and to have active, dustproducing areas that cover only $10 \%$ to $20 \%$ of its surface. There is no indication of any activity from the rest of the nucleus surface. Since the dust must be entrained by gas to be transported into the coma, it is evident that the dust-producing areas must also produce gas. The gas production from these active areas is high enough to explain the entire gas production of the comet (Keller et al., 1987).

3.2.2. UV Optical Depth. The coma is optically thin in the visible range of the spectrum, so solar radiation can freely penetrate to the nucleus, warming it and sublimating the icy component. However, in the UV range of the spectrum, molecular continuum cross sections for dissociation and ionization make the coma optically thick for active comets at heliocentric distances of less than about 1.5 AU (Huebner and Giguere, 1980). For this reason, dissociation and ionization cannot occur near the surface of the nucleus. The gas must expand to about $100 \mathrm{~km}$ before radicals and ions are formed in sufficient quantities to initiate chemical reactions. At larger heliocentric distances, the gas production is sufficiently low to decrease the attenuation of solar UV, so dissociation and ionization occur everywhere in the coma down to the nucleus. 
3.2.3. Dust as an Extended Source of the Coma. Closely associated with the dust are the extended sources of gas production in the coma. It was found that only about one-third of the $\mathrm{CO}$ is released directly from the nucleus. Two-thirds are released slowly over a distance of about $10^{4} \mathrm{~km}$ from an extended source in the coma. This conclusion comes from the work of Eberhardt et al. (1987). If the $\mathrm{CO}$ were released directly from the nucleus, then its density in the coma should decrease with the square of the inverse distance, assuming the velocity to be about constant. Thus, multiplying the density of the CO by $R^{2}$ should result in a constant value, when plotted as a function of $R$. As Fig. 11 shows, this is not the case close to the nucleus. Since the density is small at large distances, the signal-to-noise becomes large, causing the scatter in the data at large $R$. Satellite and sounding rocket observations are consistent with the assumed nucleus and extended coma sources (Feldman, this volume). It is suspected that the $\mathrm{CO}$ comes from the disintegration of the dust. Huebner and Boice (1989) have modeled the CO production, assuming that the $\mathrm{CO}$ is produced from polyoxymethylene (polymerized formaldehyde or POM) in the dust. The POM is slowly released over a distance of about $10^{4} \mathrm{~km}$, then dissociates into various POM fragments, with the final product being formaldehyde, which then rapidly dissociates to form $\mathrm{CO}$. It also produces some $\mathrm{CH}_{2}$ and $\mathrm{CH}$. This scenario is most attractive, because it not only forms $\mathrm{CO}$ in agreement with the observations (see Fig. 12a), but also is the source of $\mathrm{H}_{2} \mathrm{CO}$ (see Fig. $12 \mathrm{~b}$ and Krankowsky, this volume) and $\mathrm{CH}_{n}$ ions that are difficult to explain if the $\mathrm{CH}_{4}$ abundance is indeed as low as airborne observations indicate (Kawara et al., 1988). It also has the advantage of explaining, at least in part, the ion mass spectra from the PICCA instrument (Mitchell et al., 1986) on Giotto and the Plasmag-1 analyzer on VEGA (Gringauz et al., 1986). These instruments show spectra that are consistent with POM fragments up to a mass of $105 \mathrm{amu}$.

3.2.4. Radiation Pressure. Radiation pressure acts on each atomic and molecular species and dust particles differently, depending on their spectral properties in the visible spectrum. This pressure produces accelerations on the order of 1 to 200 times that of solar gravity on light atoms or on small dust particles. In general, the force due to radiation pressure is given by

$$
m \frac{d v}{d t}=\int \frac{F_{\nu}}{r^{2}} \frac{h \nu}{c} \sigma(\nu) d \nu
$$

where $m$ is the mass of the particle, $F_{\nu}$ the photon flux from the Sun at frequency $\nu, h \nu / c$ the momentum of a photon, $\sigma$ the cross section of the particle at frequency $\nu$, and $r$ the heliocentric distance of the comet in AU. The cross section for an atom or molecule is

$$
\sigma(\nu)=\frac{\pi e^{2}}{m c} f L_{\nu},
$$

where $f$ is the oscillator strength and $L_{\nu}$ is the spectral line shape. Clearly, molecules that have strong absorption lines, i.e., large oscillator strengths in the visible spectrum, accelerate the most. The acceleration is often expressed in terms of the fluorescence rate or $g$-factor $\left[F_{\nu} \sigma(\nu)\right]$

For atomic hydrogen, the only important transition is the Lyman- $\alpha$ resonance transition at $1216 \AA$. In that case, the acceleration is about $0.3 \mathrm{~cm} / \mathrm{s}^{2}$. With this acceleration acting over $10^{6} \mathrm{~s}$, the lifetime for photoionization and charge exchange of $\mathrm{H}$ at $1 \mathrm{AU}$, the velocity due to radiation pressure is about $3 \mathrm{~km} / \mathrm{s}$, resulting in a tailward displacement of $1.5 \cdot 10^{6} \mathrm{~km}$.

These effects are particularly important for understanding the hydrogen Lyman- $\alpha$ emission. The $\mathrm{H}$ atoms liberated in the reaction $\mathrm{H}_{2} \mathrm{O}+h \nu \rightarrow \mathrm{H}+\mathrm{OH}$ have an average excess energy of about $3.4 \mathrm{eV}$, or a velocity of about $25 \mathrm{~km} / \mathrm{s}$, if all the energy is transformed into kinetic energy. However, in the dissociation process, the $\mathrm{OH}$ radical is left in excited states of rotation and vibration, as was shown by Crovisier (1989). Since the photo rate coefficient for this process is about $10^{-5} \mathrm{~s}^{-1}$ for the quiet Sun at a heliocentric distance of $1 \mathrm{AU}$, some fraction of the $\mathrm{H}$ atoms are liberated inside the collisional sphere. However, only a small fraction of these are thermalized, because of the small mass of the hydrogen atoms relative to the average mass of the molecules making up the bulk 


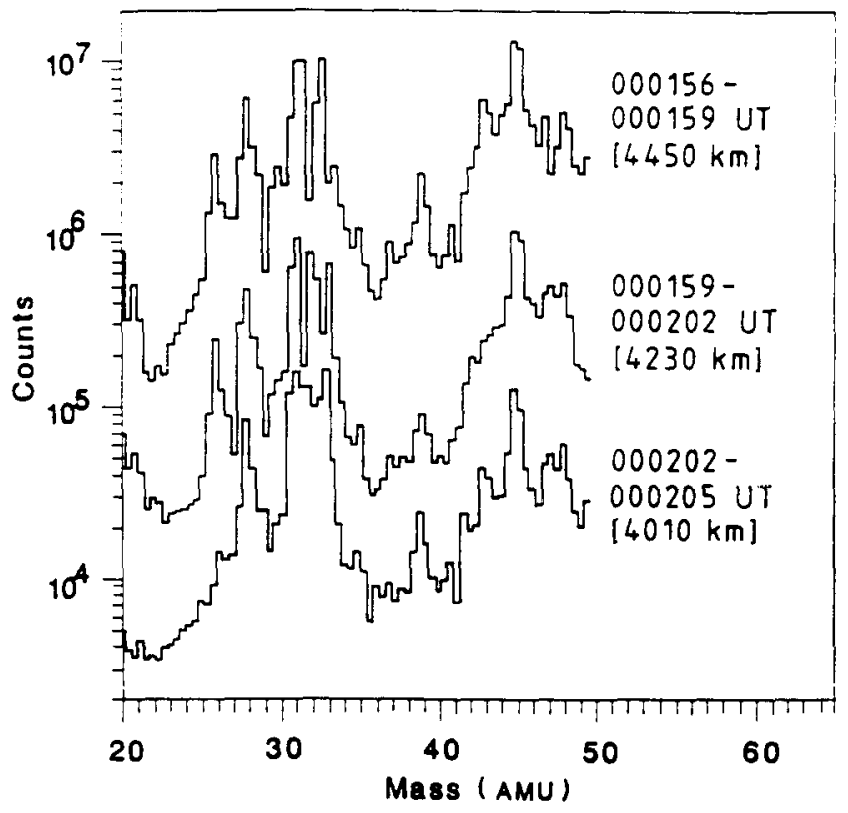

Fig. 9. Three consecutive measurements of mass spectra obtained with the PICCA instrument on Giotto. The time is given in spacecraft event time and corresponds to cometocentric distances of (top to bottom) 4450, 4230, and $4010 \mathrm{~km}$. (Courtesy Korth et al., 1989.)

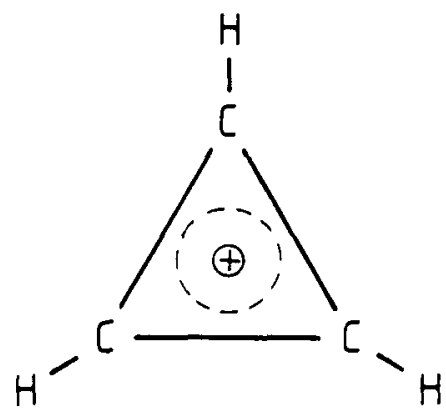

Fig. 10. The structure of $\mathrm{C}_{3} \mathrm{H}_{3}^{+}$, the cyclopropenyl cation. (Courtesy Korth et al., 1989.)

gas. Most of the $\mathrm{H}$ atoms are released outside of the collision-dominated zone. These appear as a population of fast $\mathrm{H}$ atoms. In the exosphere, $\mathrm{H}$ atoms are ionized both by solar photons and by charge exchange reactions with solar wind protons. The expansion velocity and the typical lifetime of $10^{6} \mathrm{~s}$ explain why the hydrogen coma should be on the order of $10^{7} \mathrm{~km}$ in size, as originally pointed out by Biermann (1968). 


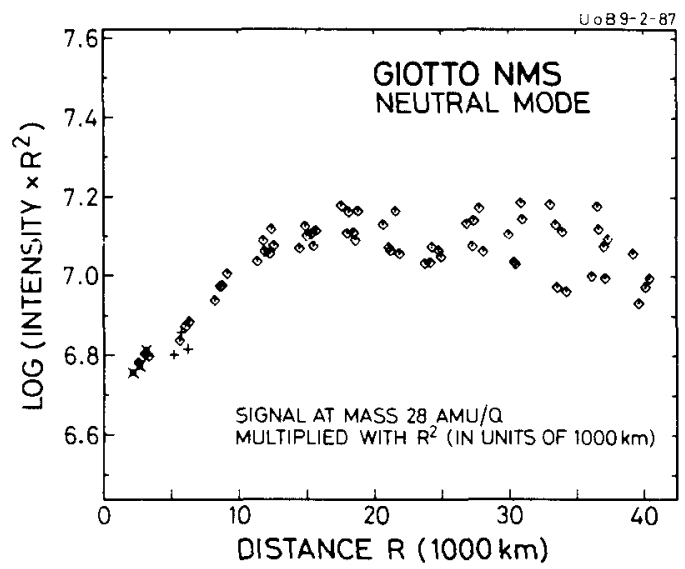

Fig. 11. Ion current in M-analyzer at mass $28 \mathrm{amu} / \mathrm{e}$ multiplied with the square of the distance. Different symbols refer to different detector gains. The increase observed for distances less than $20,000 \mathrm{~km}$ shows that a parent molecule or dust particles must be decaying into fragments contributing to the mass $28 \mathrm{amu} / \mathrm{e}$ signal. (Courtesy Eberhardt et al., 1987.)

There is a separate population of $\mathrm{H}$ atoms released in the reaction $\mathrm{OH}+h \nu \rightarrow \mathrm{O}+\mathrm{H}$, and these have an excess energy of about $1.3 \mathrm{eV}$, corresponding to an average velocity of $15 \mathrm{~km} / \mathrm{s}$. Since much of the $\mathrm{OH}$ is produced outside the collisional radius and since its mean lifetime at $1 \mathrm{AU}$ is $1.5 \cdot 10^{4} \mathrm{~s}$ (but varying with solar activity and with the heliocentric radial velocity of the radical; van Dishoeck and Dalgarno, 1984), only a very small fraction of these atoms will be thermalized. Both populations of $\mathrm{H}$ atoms are influenced by radiation pressure.

\section{Progressive Separation of Species Into a Multifluid}

\subsection{THERMAL EVOLUTION OF NEUTRAL SPECIES}

Once a volume of gas has expanded and moved beyond the collision-dominated zone, free molecular flow applies. Models valid for this region have been developed by Festou (1981a, 1981b), Kitamura et al. (1985), and Combi and Smyth (1988a, 1988b). Festou's model is usually referred to as the vectorial model, while the model of Combi and Smyth is a Monte Carlo calculation. All of these models assume a radial emission of molecules from the collision-dominated inner coma. Daly and Jockers (1989) consider expansion along Keplerian orbits over large distances. The model of Huebner and Keady (1984) and Huebner (1985) discusses a transition to free molecular flow in the molecular kinetics approximation. At this time, there is no model that assumes free molecular flow directly from the surface of the nucleus as should be expected for comets at large heliocentric distances; an aspect that will be important for the Comet Rendezvous Asteroid Flyby (CRAF) mission to Comet Kopff near aphelion. Free molecular flow may also be of importance on the night side of comets, especially if the surface wind from the day side is very weak. At large heliocentric distances, a region devoid of particles will develop in the coma, coincident with the light shadow. 

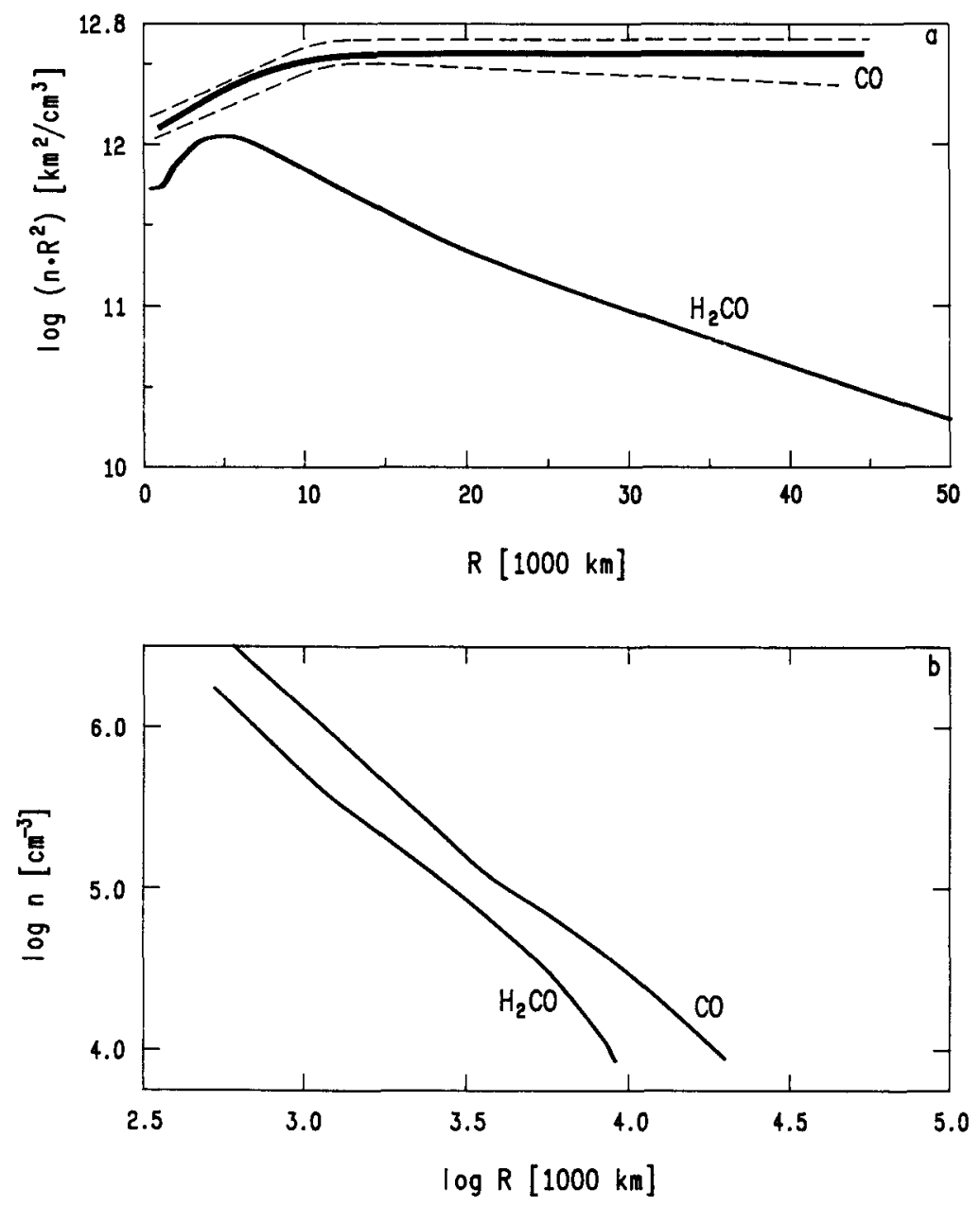

Fig. 12. (a) Model calculation of $\mathrm{CO}$ and $\mathrm{H}_{2} \mathrm{CO}$ distributed sources from POM (solid curves). The dashed curves correspond to the envelopes of the data of Fig. 10 for $\mathrm{CO}$. (b) The same data plotted as number density vs. cometocentric distance. 


\subsection{PRODUCTION AND ENERGETICS OF THE PLASMA}

Inside the contact surface, photoionization, photodissociative ionization, and collisional ionization by energetic photoelectrons are the dominant ionization processes. Dissociative recombination is the major destruction mechanism of ions. Other recombination processes are not very important. Ions can, of course, exchange charge or undergo chemical reactions, but this does not change the degree of ionization. Removal of ions into the plasma tail is also not very efficient in this region.

Outside of the contact surface, photoionization is the most important ionization process, until charge exchange and electron collisional ionization with the solar wind protons and electrons begin to compete effectively in the outermost regions of the coma. Schmidt et al. (1988) have presented the major effects on the balance of mass, momentum, and energy on the plasma along the Sun-comet axis in their three-dimensional, MHD model (see Figure 10 in their paper). New cross sections for charge exchange and recombination have now been incorporated; however, ionization by hot electrons near the contact surface has not been taken into account but may be important (Cravens, 1989).

Collective ionization by the Alfven critical velocity effect occurs when the relative kinetic energy of a neutral molecule colliding with the magnetized plasma is larger than its ionization potential, i.e., the velocity exceeds the critical velocity. Figure 13(a) compares the velocity of the cometary plasma with the critical velocity required for anomalous ionization of various coma species. A certain fraction of the surplus energy of the initial ionization is imparted to the electrons, which, under favorable conditions, enables them to ionize additional molecules. This triggers an avalanche if the timescale $\tau_{\text {ion }}$ for ionization is smaller than the travel time $\tau_{\text {travel }}$ through the supercritical range $\Delta R$. We will show that this condition cannot be satisfied in a comet, even with the most favorable assumptions; the electron receives the full kinetic energy of the relative motion of the new ion

$$
m_{\mathrm{e}} v_{\mathrm{e}}^{2} / 2=m_{\mathrm{n}} v_{\mathrm{p}}^{2} / 2,
$$

and the electron, though moving with velocity $v_{\mathrm{e}}$, stays confined within a plasma element moving with velocity $v_{\mathrm{p}}$, so that $\tau_{\text {travel }}=R / v_{\mathrm{p}}$, where $\Delta R$ is replaced by $R$. If $p^{(\mathrm{i})}$ is the probability for an electron, heated by the critical velocity effect, to ionize a neutral of species i with density $n_{\mathrm{n}}^{(\mathrm{i})}$ before it leaves the supercritical range, then the Townsend ratio is

$$
\frac{p^{(\mathrm{i})}}{1-p^{(\mathrm{i})}}=\frac{\tau_{\text {travel }}}{\tau_{\text {ion }}}<\frac{n_{\mathrm{n}}^{(\mathrm{i})} \sigma_{\mathrm{ci}}^{(\mathrm{i})} v_{\mathrm{e}} R}{v_{\mathrm{p}}},
$$

where $\sigma_{\mathrm{ci}}^{(\mathrm{i})}$ is the electron collisional ionization cross section of species $\mathrm{i}, v_{\mathrm{e}}$ is the velocity of the electron, and $v_{\mathrm{p}}$ is the plasma velocity. Figure 13(b) illustrates the ratio given in Eq. (5) as a function of cometocentric distance assuming Eq. (4). Using model parameters and cross sections from Schmidt et al. (1988) with these overly optimistic assumptions, this ratio never comes close to 1.

This result holds for comets in general. We observe that

$$
n_{\mathrm{n}}^{(\mathrm{i})}=\frac{Q^{(\mathrm{i})}}{4 \pi R^{2} v}
$$

where $Q^{(i)}$ is the gas production of species $\mathrm{i}$ and $v$ is the velocity of the neutrals. Eq. (5) reduces to

$$
\frac{p^{(\mathrm{i})}}{1-p^{(\mathrm{i})}}<\frac{Q^{(\mathrm{i})} \sigma_{c i}^{(\mathrm{i})}\left(m_{\mathrm{i}} / m_{e}\right)^{\frac{1}{2}}}{4 \pi R v} .
$$

For a crude estimate, we use the scaling law of cometary plasma flow,

$$
\frac{m_{\mathrm{C}} Q k_{\mathrm{pi}}}{4 \pi v \rho_{\mathrm{sw}} v_{\mathrm{sw}} R}=\text { const, }
$$



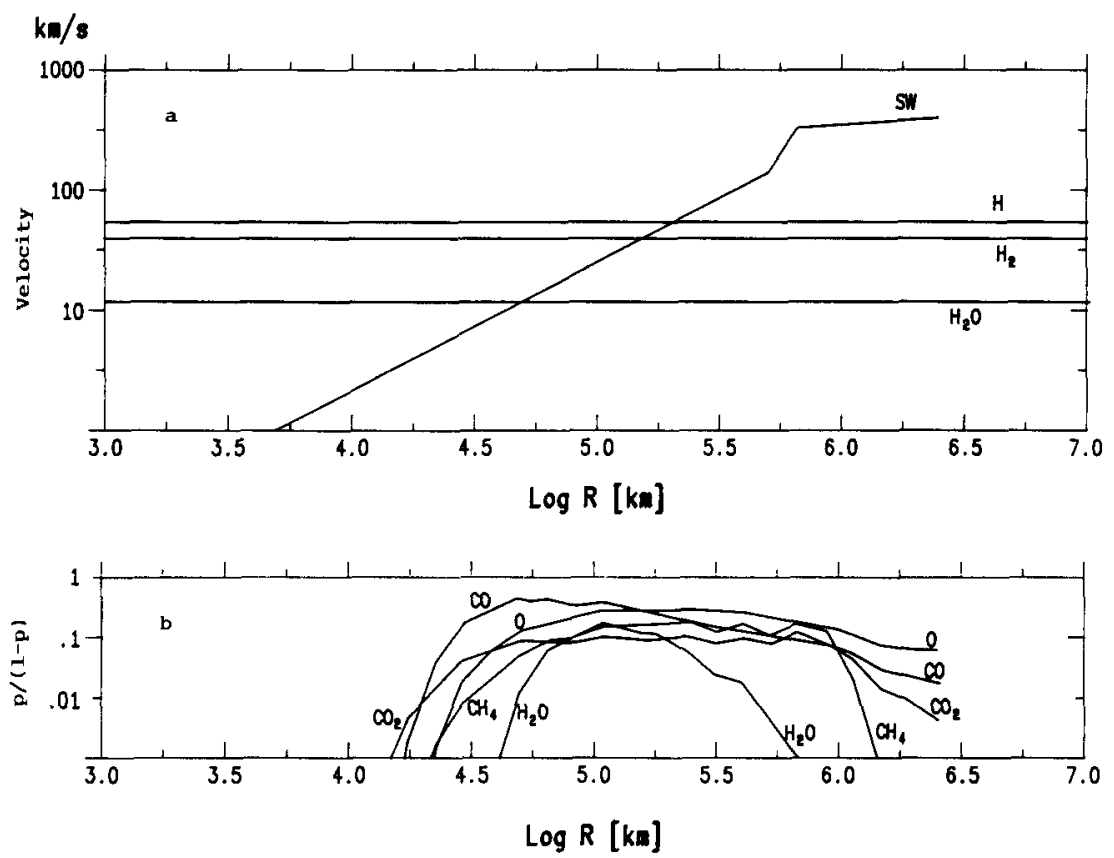

Fig. 13. Alfvén critical velocity (anomalous ionization) effect: (a) Plasma velocity vs. cometocentric distance and critical velocities. For clarity, some critical velocities have been omitted, but lie within a factor of 2 of that for $\mathrm{H}_{2} \mathrm{O}$. (b) The probability of a second ionization vs. cometocentric distance.

(Schmidt and Wegmann, 1982), where the total gas production $Q>Q^{(\mathrm{i})}$, and find

$$
\frac{p^{(\mathrm{i})}}{1-p^{(\mathrm{i})}}<\mathrm{const} \frac{\sigma_{\mathrm{ci}}^{(\mathrm{i})}\left(m_{\mathrm{i}} / m_{\mathrm{e}}\right)^{\frac{1}{2}} \rho_{\mathrm{sw}} v_{\mathrm{sw}}}{k_{\mathrm{pi}} m_{\mathrm{C}}} \frac{Q^{(\mathrm{i})}}{Q}
$$

where $\rho_{\mathrm{sw}}$ and $v_{\mathrm{sw}}$ are the mass density and the velocity of the solar wind, $k_{\mathrm{pi}}$ is the average rate of photoionization, and $m_{\mathrm{C}}$ is the mass of an average cometary ion. Since $Q^{(i)} / Q$ remains approximately constant for a comet over a wide range of heliocentric distances, we see that, in this approximation, the Townsend ratio does not depend on the gas production rate nor on the distance from the Sun, but solely on the chemical composition and the ratio of solar wind flux to the solar UV flux.

Figure 14 displays various quantities from the model calculations of Wegmann et al. (1987) as a function of cometocentric distance. The top left panel shows the log of the electron temperature. The electrons are cooled by collisions with $\mathrm{H}_{2} \mathrm{O}$ out to several thousand kilometers and therefore equilibrate to the same temperature as the coma gas. As the coma gas density decreases with increasing cometocentric distance, the electrons undergo fewer collisions and decouple from the coma gas. At this point, the electron temperature rises sharply. The second panel shows the velocity. The dashed curve is the velocity of the ions, which is dominated by the solar wind velocity at large distances. The third panel shows the electron density, which equals the surn of the densities of all the ions. The next twelve panels show the densities of various ion species. 


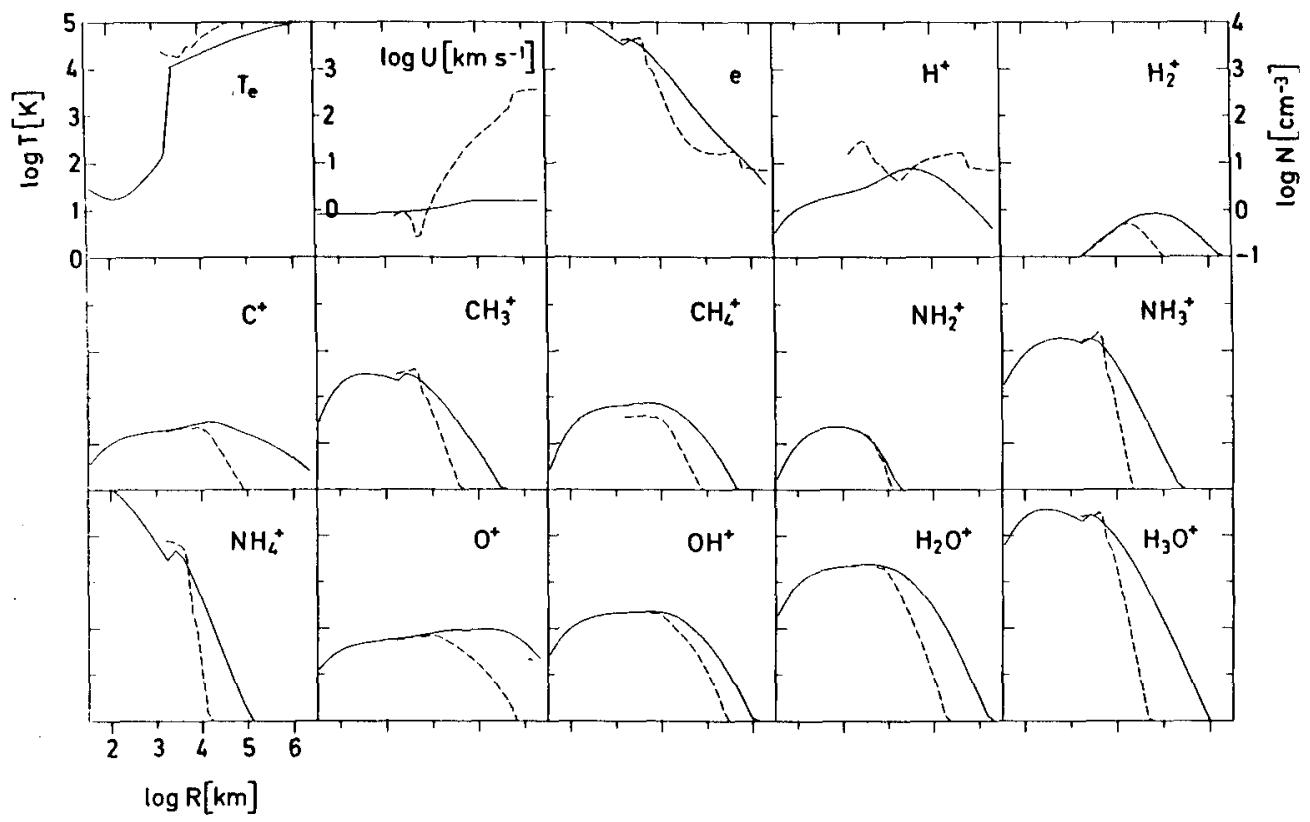

Fig. 14. (a) Electron temperature, (b) plasma velocity, (c) electron density, and (d) to (o) ion densities. Solid lines indicate the spherically symmetric model without solar wind interaction; dashed lines indicate the axisymmetric model with solar wind interaction.

\subsection{COMPARISON WITH OBSERVATIONS}

Comparing model calculations with ion mass spectrometer results, we find that the water group ions are well-explained inside the contact surface by the models of Allen et al. (1987) and Wegmann et al. (1987) and outside the contact surface with solar wind interaction by Wegmann et al. (1987). These models both assume $\mathrm{H}_{2} \mathrm{O}$ to be the dominant volatile molecule in the nucleus, with a few percent of $\mathrm{NH}_{3}$ and $\mathrm{CH}_{4}$. However, the abundances of the latter two molecules are about a factor of 10 higher than spectroscopic observations indicate. Somewhat better agreement with the IMS data is obtained if one assumes only a few tenths of one percent of $\mathrm{NH}_{3}$ and $\mathrm{CH}_{4}$ in the nucleus and contributions from a distributed source, probably from CHON particles, on the order of $1 \%$.

The groups of ions clustered around 30 amu and 45 amu in the IMS data are not well-understood. Heavy molecules are needed to explain these two groups. However, there are only a few volatile species that seem like plausible sources for the heavy molecules: $\mathrm{HCN}, \mathrm{H}_{2} \mathrm{CO}, \mathrm{NH}_{2} \mathrm{CH}_{3}, \mathrm{CH}_{3} \mathrm{OH}$, $\mathrm{H}_{2} \mathrm{C}_{3} \mathrm{H}_{2}, \mathrm{H}_{2} \mathrm{COO}$, etc. Most heavy molecules are very likely refractory organic compounds that are associated with the CHON dust particles. These molecules are rich in $\mathrm{NH}_{n^{-}}$and $\mathrm{CH}_{n^{-}}$-bearing compounds, making an abundance of several percent of $\mathrm{NH}_{3}$ and $\mathrm{CH}_{4}$ unnecessary.

\section{Plasma Flow}

We discuss plasma flow only insofar as it influences the chemistry and composition. The details of the physics of the plasma flow have been discussed by us recently (Schmidt et al., 1988) and will be discussed in another paper in this volume. 


\subsection{SOLAR WIND INTERACTION AND COUPLING BY COLLISIONS AND MAGNETIC FIELDS}

Cometary neutral molecules stream approximately radially outward from the nucleus. Deviation from exact radial motion is caused by asymmetric outgassing of the nucleus, collisions with ions (the ion-neutral drag), and radiation pressure with increasing cometocentric distance. The neutral species are progressively more ionized by photoionization and by charge exchange with the solar wind. The solar wind velocity decreases as the solar wind picks up the heavier ions from the comet. At distances on the order of $10^{5} \mathrm{~km}$, several experiments have found cometary ion speeds systematically lower than the local solar wind speed (B. Goldstein et al., 1987; Galeev et al., 1987; Fuselier et al., 1988; Formisano et al., 1990; Coates et al., 1990).

Figure 15 gives a possible explanation for this process. It shows the co-moving ion distributions in velocity space relative to the magnetic field and the solar wind. The solar wind ions fill shells centered around the solar wind velocity vector. The heavy ions are picked up by the solar wind and are first distributed into a ring beam. Before it is transformed into a solar wind concentric shell by pitch angle scattering, this ring beam is centered on a velocity vector that is the projection of the solar wind vector onto the plane perpendicular to the magnetic field. Consequently, these ions have a smaller bulk speed than solar wind ions, and, relative to the latter, they drift asymmetrically towards the Sun-comet axis along the magnetic field. The nearly symmetric solar wind velocity vectors and the asymmetric velocity vectors of the newborn cometary pickup ions are given in Fig. 16 at two locations, $3 \cdot 10^{5} \mathrm{~km}$ from the nucleus on opposing sides.

$\bar{B}$ (ON DRAPING FIELDLINE)

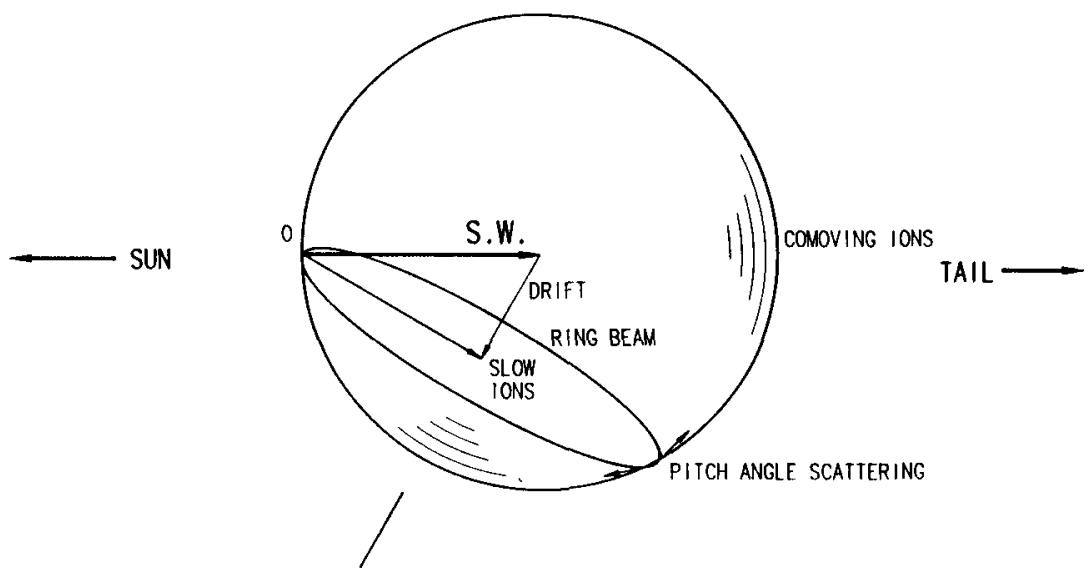

NUCLEUS

Fig. 15. Proton and water group ion distributions in velocity space. 


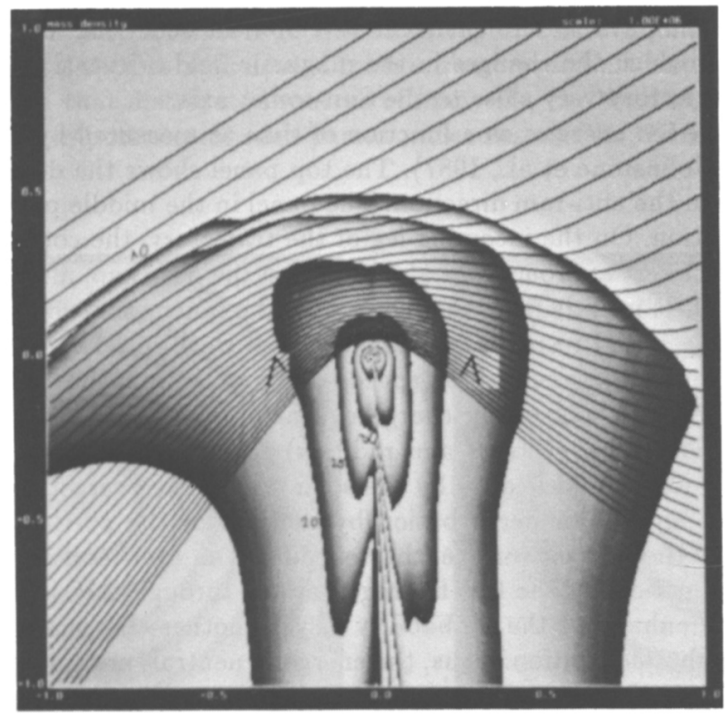

Fig. 16. The asymmetric drift velocities of the water group ions. Illustrated are the draped field lines, contours of magnetic field strength, the nearly symmetric solar wind velocities, and the asymmetric water group drift velocities in two locations, east and west of the nucleus.

Figure 17 shows the number flux and the mass flux crossing the plane perpendicular to the Sun-comet axis at two different scales for the MHD model. In the outermost region, both fluxes are still dominated by solar protons and show a nearly symmetric enhancement just inside the bow shock, which is strongly inclined so that the flow is diverted outward. The particle flux consequently exhibits a global depression, whereas the mass flux forms a plateau due to the contribution from cometary ions growing towards the nucleus. This separation of the diverted solar wind flux from the flux of heavy cometary ions, originating from the inner coma, will be further enhanced when the above-mentioned non-MHD drift of heavy ring beam ions towards the Sun-comet axis is taken into account.

In the inner region, the plasma is saturated with heavy cometary ions so that the two contour maps of particle and mass flux become indistinguishable (see Fig. 17). Both clearly exhibit an asymmetric enhancement of the cometary fluxes along the vertical, i.e., perpendicular to the magnetic field. The asymmetry in the plasma flow induced by the magnetic field also causes asymmetries in the chemical evolution along the flow, depending on the difference in azimuth between the local plane of a flowline and the local direction of the co-moving magnetic field, because the Lorentz force accelerates the plasma only perpendicular to the field. The azimuth of the field, measured at Giotto, changed very often and quite rapidly. Any spacecraft on the VEGA or Giotto trajectories passing through this flow will record a sudden increase in the average ion mass, similar to the boundary that has become known as the cometopause. The spacecraft data do not represent a single flow tube, but an average of many flow tubes. If we consider a reference frame in which the magnetic field is fixed in space, then Figure 18 illustrates the positions at which the spacecraft sampled the plasma. In Figure 18(a), points representing the azimuthal orientation of the magnetic field have been entered as recorded by the Giotto spacecraft. These points represent 2.5 -minute averages. From this presentation, it is clear that the spacecraft sampled the plasma in a broad variety of azimuthal positions, and all asymmetries in the flow due to magnetic effects will cause rapid fluctuations. In our global, stationary, MHD model, many of the measured quantities are nearly axisymmetric, but there exist large fluctuations in $\beta$, the ratio of gas pressure to magnetic 
pressure, as shown in Figure 18(b). This is an important consideration for the CRAF mission. If it is required to measure the physical and chemical development occurring in a flow tube, then a flow tube must be chosen in which the changes in the magnetic field orientations are a minimum. This will be the case in a trajectory very close to the Sun-comet axis.

Figure 19 shows the ion energies as a function of time as measured by the JPA instrument on the Giotto spacecraft (Johnstone et al., 1987). The top panel shows the data in the ram direction, and the bottom panel, in the anti-ram direction. The panel in the middle presents data between the ram and anti-ram direction. On the incoming leg of the trajectory, the contact surface was crossed at about $4000 \mathrm{~km}$, and closest approach was at $600 \mathrm{~km}$ (in the data gap, after the spacecraft was hit by a large dust particle). It is clear from the figure that the inner coma contains ions with energies up to $10 \mathrm{keV}$. This unexpected result is explained by the work of Eviatar et al. (1989), which is presented in Fig. 20. Neutral molecules with speeds of about $1 \mathrm{~km} / \mathrm{s}$ move radially outward in the coma. Some of them are then ionized by charge exchange with the mass-loaded solar wind. The neutralized solar wind ions (heavy atoms and radicals) continue toward the inner coma, while at the same time, the new ions are picked up by the solar wind. The energetic neutrals penetrate the contact surface without any major perturbation by the ions or the piled-up magnetic field. Once these neutrals are inside the contact surface, they encounter an ever-increasing density of the coma gas, randomizing the directions of the fast hydrogen atoms through collisions without a significant loss of their energy and enhancing the probability of yet another charge exchange with coma ions that were produced by photoionization. Thus, the energetic neutrals are converted into the energetic ions that have been detected inside of the contact surface. The importance of this is twofold: not only are there energetic ions as measured by the JPA instrument, but there must also be energetic neutrals. These energetic particles can undergo hot chemical reactions. A number of these reactions from the work of Heyl et al. (1989) are indicated below, in Table 5.

Table 5. Some Suprathermal Reactions

\begin{tabular}{lll}
\hline $\overrightarrow{\mathrm{H}}+\mathrm{H}_{2} \mathrm{O} \rightarrow \mathrm{OH}+\mathrm{H}+\mathrm{H}$ & $\overrightarrow{\mathrm{H}}_{2}+\mathrm{CN} \rightarrow \mathrm{HCN}+\mathrm{H}$ & $\overrightarrow{\mathrm{N}}+\mathrm{H}_{2} \mathrm{O} \rightarrow \mathrm{NH}+\mathrm{OH}$ \\
$\overrightarrow{\mathrm{H}}+\mathrm{H}_{2} \mathrm{O} \rightarrow \mathrm{OH}+\mathrm{H}_{2}$ & $\overrightarrow{\mathrm{C}}+\mathrm{H}_{2} \mathrm{O} \rightarrow \mathrm{CO}+\mathrm{H}+\mathrm{H}$ & $\overrightarrow{\mathrm{N}}+\mathrm{CN} \rightarrow \mathrm{C}+\mathrm{N}_{2}$ \\
$\overrightarrow{\mathrm{H}}+\mathrm{CH}_{4} \rightarrow \mathrm{CH}_{3}+\mathrm{H}_{2}$ & $\overrightarrow{\mathrm{C}}+\mathrm{H}_{2} \mathrm{O} \rightarrow \mathrm{CO}+\mathrm{H}_{2}$ & $\overrightarrow{\mathrm{O}}+\mathrm{H}_{2} \mathrm{O} \rightarrow \mathrm{OH}+\mathrm{OH}$ \\
$\overrightarrow{\mathrm{H}}+\mathrm{CO} \rightarrow \mathrm{C}+\mathrm{OH}$ & $\overrightarrow{\mathrm{C}}+\mathrm{N}_{2} \rightarrow \mathrm{CN}+\mathrm{N}$ & $\overrightarrow{\mathrm{O}}+\mathrm{H}_{2} \mathrm{O} \rightarrow \mathrm{II}_{2} \mathrm{O}_{2}{ }^{*}$ \\
\hline
\end{tabular}

\section{Conclusions}

\subsection{DEDUCED PROPERTIES AND COMPOSITION OF THE NUCLEUS}

Our understanding of comets has been dramatically enriched by the brief glimpses of Comet Halley obtained from spacecraft flybys lasting only hours total and only minutes in the inner coma close to the nucleus. During the several years since these encounters, our general concept of the nucleus has changed. Gas and dust jets observed in the coma bear out the asymmetric gas production from a much lower percentage of the surface than expected. The measured dust-to-gas mass ratio of approximately 2 in the coma (McDonnell et al., 1990), when extrapolated back to the nucleus, strongly suggests that the nucleus is better described as a "snowy dirtball" than as the "dirty snowball" originally proposed by Whipple (1950). Theoretical calculations of the energy balance at the nucleus, assuming sublimation of volatiles is controlled by $\mathrm{H}_{2} \mathrm{O}$, are in good agreement with the observed gas production. The volatile composition is dominated by water (approximately $80 \%$ ) and 
contains CO. Other ices are presumed to exist in smaller abundances. The dust consists of silicate particles, CHON particles, and a mixture of these two types. Observations are consistent with the notion that some coma gas species are released from refractory organic compounds contained in the dust. It is quite probable that distributed sources of many H-, C-, N-, and O-bearing coma species from the dust lessen the importance of such parent molecules as $\mathrm{CH}_{4}, \mathrm{NH}_{3}$, and possibly others in the nucleus.

a

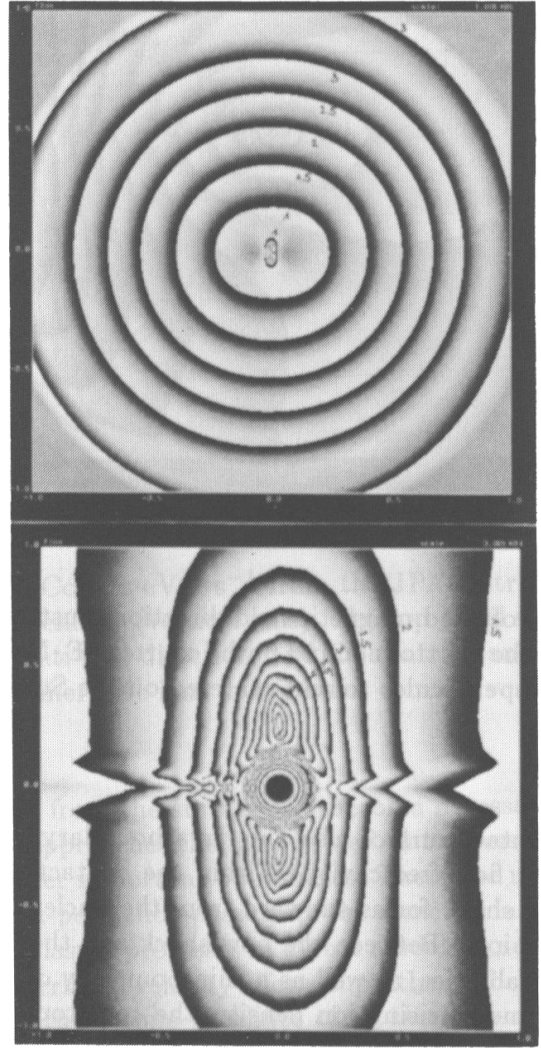

b

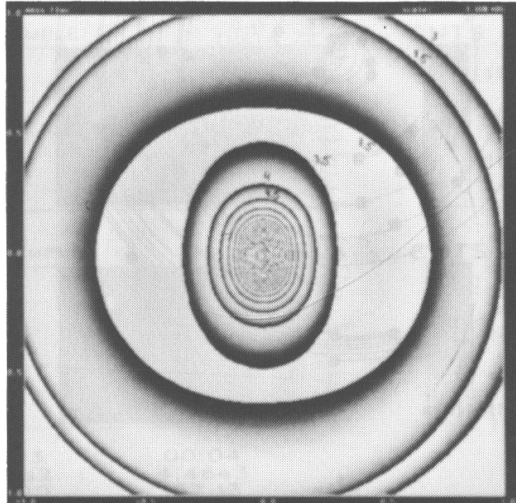

d

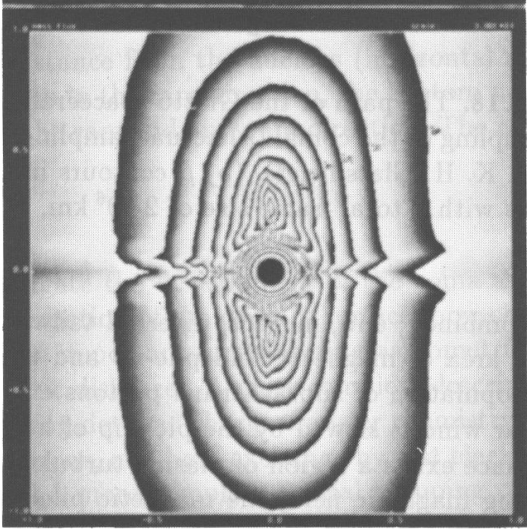

Fig. 17. Mass flux and particle flux of ions in the coma: (a) and (c) particle flux contours, and (b) and (d) mass flux contours with frame sizes of $2 \cdot 10^{6} \mathrm{~km}$ for (a) and (b); $6 \cdot 10^{4} \mathrm{~km}$ for (b) and (d).

\subsection{SUMMARY OF THE COMET ENVIRONMENT}

The gas and dust production is asymmetric, arising from isolated active areas of the surface. The spatial distribution of the bulk neutral gas quickly becomes spherical, whereas the ions are greatly affected by the interaction with the solar wind beyond a few thousand kilometers. The pressure balance of outwardly streaming cometary gas and the opposing flow of the mass-loaded solar wind and magnetic field gives rise to the contact surface. An inner shock is expected to exist just interior to the contact surface as the supersonic expansion of the cometary ions is slowed, 

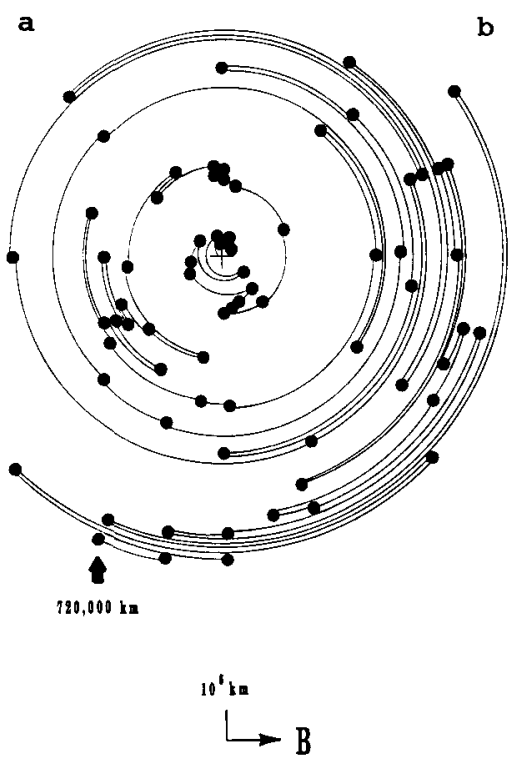

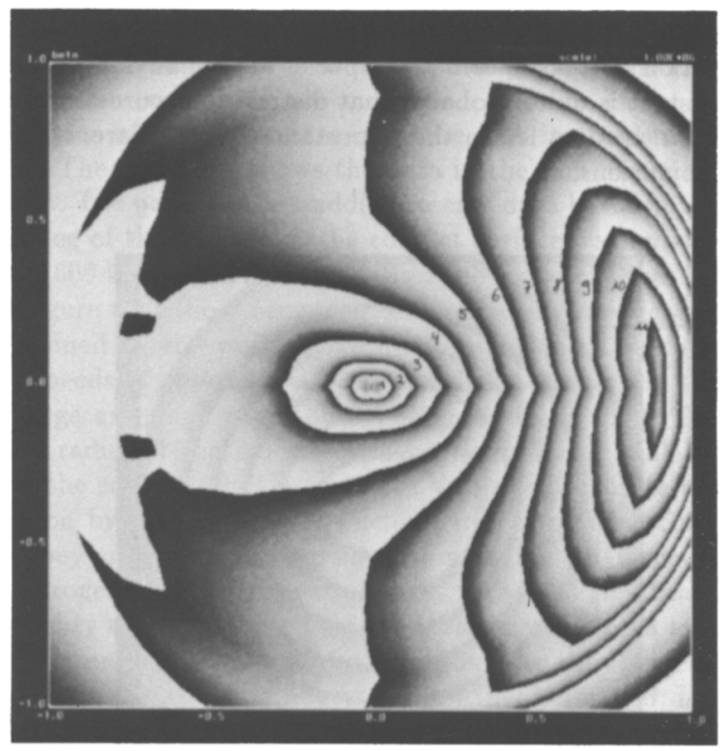

Fig. 18. The path of the Giotto spacecraft in a frame of fixed magnetic field direction illustrates the sampling of the coma: (a) actual sampling points on the Giotto inbound path (courtesy F. Neubauer and K. H. Glassmeier), (b) $\beta$ contours in a plane perpendicular to and centered on the Sun-comet axis with a total frame size of $2 \cdot 10^{6} \mathrm{~km}$.

recombined, and, in part, diverted tailward. The contact surface also acts as a boundary between the area of magnetic field pile-up and the magnetic field-free cavity. Within the contact surface, a population of suprathermal protons exists. A bow shock forms sunward from the nucleus as the solar wind is slowed by the pick-up of heavier comet ions. Between the bow shock and the contact surface exists a region of plasma turbulence and instabilities, as well as a thin boundary of rapidly rising magnetic field, the magnetic pile-up region, and of rising ion density, the cometopause. At the largest cometary distance scales, the H Lyman- $\alpha$ coma was found to be consistent with $\mathrm{H}$ atom photodissociation products from the inner coma.

\subsection{OUTSTANDING PROBLEMS AND DIRECTIONS FOR FUTURE WORK}

The chemical composition of the nucleus has been inferred from the coma observations, but its exact makeup remains open to debate. Further analysis of the in situ measurements of the coma will suggest how intimately the gaseous species are related to the dust and what implications this has for the nature of the nucleus. Basic laboratory work on the gas-phase chemistry and the volatility of large organic molecules and oligomer products, both ionic and neutral, is needed to understand this connection between the gas and solid phase constituents of the coma. The distribution of the neutral species in the coma is described well by global models out to cometocentric distances of a few hundred thousand kilometers, where the effects of radiation pressure need to be considered in the global models. The effects of energetic protons on the chemistry in the inner coma need to be incorporated also. At large heliocentric distances, models of the free molecular flow of coma species 

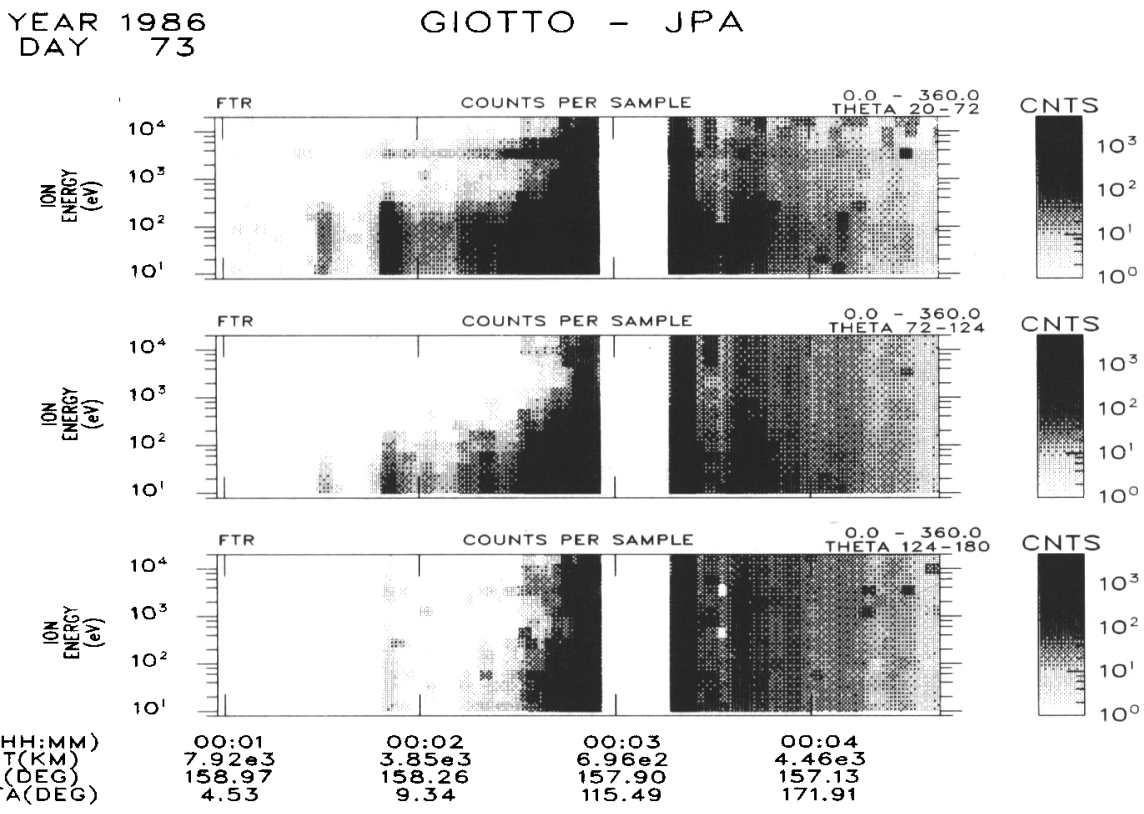

Fig. 19. Counts $\mathrm{eV}^{-1} \mathrm{~s}^{-1}$ from the JPA instrument vs. distance from the nucleus (horizontal axis) and ion energy (vertical axis). The top panel shows the data in the ram direction, the bottom panel, in the anti-ram direction, and the central panel, between the ram and anti-ram direction. The count rate of energetic ions in the inner coma is very high.

directly from the surface will become necessary to investigate the development of the coma as the comet approaches the Sun, as well as to investigate the formation of the contact surface, bow shock, and other important boundaries. The same models will be important for analyzing asymmetries in the post-perihelion passage of the comet at large heliocentric distances. A more complete description of the plasma processes in global models is needed, including detailed charge transfer chemistry, the Alfvén critical velocity effect, suprathermal chemical reactions, and heat exchange by fast electrons. When longer time baselines of in situ measurements and a more complete spatial mapping of the cometary environment become available from the CRAF and Rosetta missions (and for the premission planning of such projects), it will be important to generalize the current global models to a time-dependent formulation and to three dimensions to further our knowledge of cometary science. 


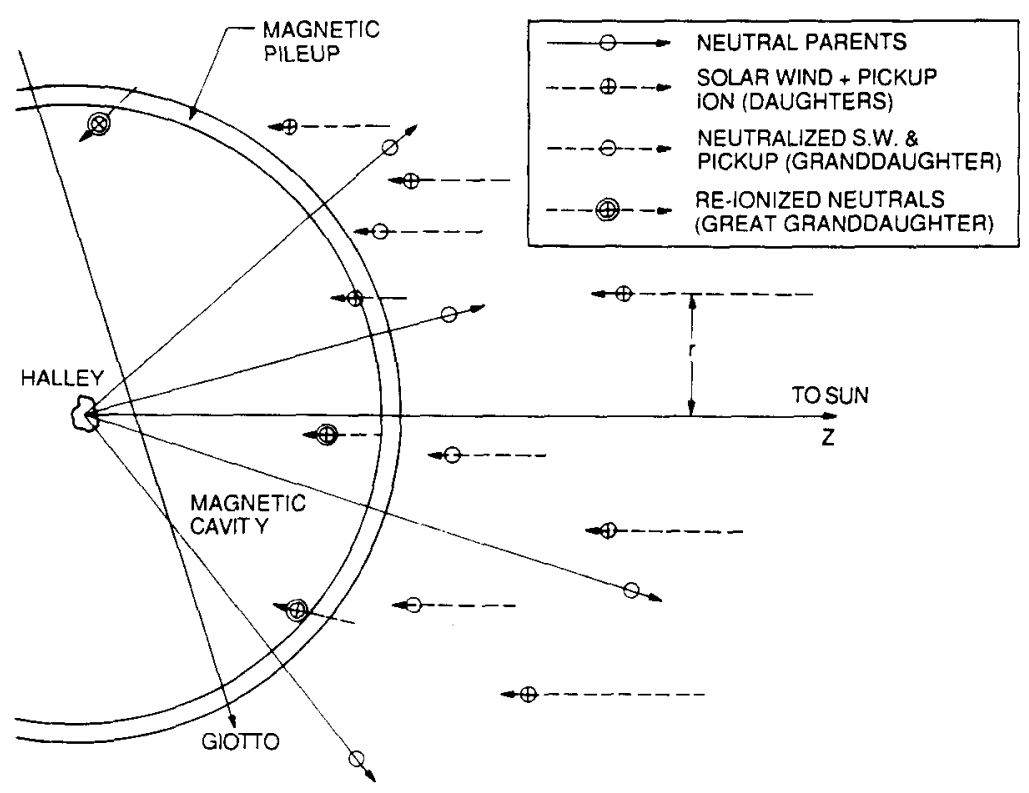

Fig. 20. Schematic diagram explaining the high count rate of the energetic ions in the inner coma. (Courtesy Eviatar et al., 1989.)

\section{References}

A'Hearn, M. F. (1982) 'Spectrophotometry of comets at optical wavelengths,' in L. L. Wilkening (ed.), Comets, University of Arizona Press, Tucson, pp. 433-460.

A'Hearn, M. F., and Cowan, J. J. (1980) 'Vaporization in comets: The icy grain halo of comet West,' Moon Planets 23, 41-52.

A'Hearn, M. F., Feldman, P. D., and Schleicher D. G. (1983) 'The discovery of $\mathrm{S}_{2}$ in comet IRASAraki-Alcock 1983d,' Astrophys. J. 274, L99-L103.

A'Hearn, M. F., Hoban, S., Birch, P. V., Bowers, C., and Klinglesmith, D. A., III (1986) 'Cyanogen jets in comet Halley,' Nature 324, 649-651.

Allen, M., Delitsky, M., Huntress, W., Yung, Y., Ip, W.-H., Schwenn, R., Rosenbauer, H., Shelley, E., Balsiger, H., and J. Geiss (1987) 'Evidence for methane and ammonia in the coma of comet P/Halley,' Astron. Astrophys. 187, 502-512.

Balsiger, H., Altwegg, K., Bühler, F., Geiss, J., Ghielmetti, A. G., Goldstein, B. E., Goldstein, R., Huntress, W. T., Ip, W.-H., Lazarus, A. J., Meier, A., Neugebauer, M., Rettenmund, U., Rosenbauer, H., Schwenn, R., Sharp, R. D., Shelley, E. G., Ungstrup, E., and Young, D. T. (1986) 'Ion composition and dynamics at comet Halley,' Nature 321, 330-334.

Biermann, L. (1968) 'On the emission of atomic hydrogen in comets', in JILA Report 93.

Bockelée-Morvan, D., and Crovisier, J. (1985) 'Possible parents for the cometary cyanogen radical: Photochemistry and excitation conditions,' Astron. Astrophys. 151, 90-100.

Clairemidi, J., Moreels, G., and Krasnopolsky, V. A. (1990) 'Spectro-imagery of P/Halley's inner coma in the $\mathrm{OH}$ and $\mathrm{NH}$ ultraviolet bands,' Astron. Astrophys. 231, 235-240. 
Coates, A. J., Johnstone, A. D., Thomsen, M. F., Formisano, V., Amata, E., Wilken, B., Jockers, K., Winningham, J. D., Borg, H., and Bryant, D. A. (1987) 'Solar wind flow through the comet P/Halley bow shock,' Astron. Astrophys. 187, 55-60.

Coates, A. J., Wilken, B., Johnstone, A. D., Jockers, K., Glassmeier, K.-H., and Huddleston, D. E. (1990) 'Bulk properties and velocity distributions of water group ions at comet Halley: Giotto measurements,' J. Geophys. Res. 95, 10249-10260.

Cochran, A. L. (1985) ' $\mathrm{C}_{2}$ photolytic processes in cometary comae', Astrophys. J. 289, 388-391.

Cochran, W. D., and Cochran, A. L. (1990) ' $\mathrm{NH}_{2}$ in comet Halley,' in C.-I. Lagerkvist, H. Rickman, B. A. Lindblad, and M. Lindgren (eds.), Asteroids, Comets, and Meteors III, Reprocentralen HSC, Uppsala, pp. 289-292.

Combi, M. R. (1978) 'Convolution of cometary brightness profiles by circular diaphragms,' Astron. J. $83,1459-1466$.

Combi, M. R. (1989) 'The outflow speed of the coma of Halley's comet,' Icarus 81, 41-50.

Combi, M. R., and Delsemme, A. H. (1980) 'Brightness profiles of $\mathrm{CO}^{+}$' in the ionosphere of comet West (1976 VI),' Astrophys. J. 238, 381-387.

Combi, M. R., and Delsemme, A. H. (1986) 'Neutral cometary atmospheres. V. $\mathrm{C}_{2}$ and CN in comets,' Astrophys. J. 308, 472-484.

Combi, M. R., and Smyth, W. H. (1988a) 'Monte Carlo particle-trajectory models for neutral cometary gases. I. Models and equations,' Astrophys. J. 327, 1026-1043.

Combi, M. R., and Smyth, W. H. (1988b) 'Monte Carlo particle-trajectory models for neutral cometary gases. II. The spacial morphology of the Lyman-alpha coma,' Astrophys. J. 327, 1044-1059.

Cosmovici, C. B., Schwarz, G., Ip, W.-H., and Mack, P. (1988) 'Gas and dust jets in the inner coma of Comet Halley,' Nature 332, 705-709.

Cravens, T.E. (1989) 'A magnetohydrodynamic model of the inner coma of comet Halley,' J. Geophys. Res. 94, 15025-15040.

Crifo, J. F. (1987) 'Improved gas-kinetic treatment of cometary water sublimation and recondensation: Application to comet P/Halley,' Astron. Astrophys. 187, 438-450.

Crovisier, J. (1989) 'On the photodissociation of water in cometary atmospheres,' Astron. Astrophys. 213, 459-464.

Cucchiaro, A., and Malaise, D. (1982) 'Dynamic coma models for Comet Bennett 19701I,' Astron. Astrophys. 114, 102-108.

Daly, P. W, and Jockers, K. (1989) 'The effects of Kepler orbits on the distribution of neutrals and ions around comet Halley,' Adv. Space Res. 9(3), 235-238.

Eberhardt, P., Krankowsky, D., Schulte, W., Dolder, U., Lämmerzahl, P., Berthelier, J. J., Woweries, J., Stubbemann, U., Hodges, R. R., Hoffman, J. H., and Illiano, J. M. (1987) 'The CO and $\mathrm{N}_{2}$ abundance in comet P/Halley,' Astron. Astrophys. 187, 481-484.

Encrenaz, T., d'Hendecourt, L., and Puget, J. L. (1988) 'The interpretation of the $3.2-3.5 \mu \mathrm{m}$ emission feature in the spectrum of comet P/Halley: Abundances in the comet and in interstellar matter,' Astron. Astrophys. 207, 162-173.

Eviatar, A., Goldstein, R., Young, D. T., Balsiger, H., Rosenbauer, H., and Fuselier, S. (1989) 'Energetic ion fluxes in the inner coma of comet P/Halley,' Astrophys. J. 339, 545-557.

Festou, M. C. (1981a) 'The density distribution of neutral compounds in cometary atmospheres. I. Models and equations,' Astron. Astrophys. 95, 69-79.

Festou, M. C. (1981b) 'The density distribution of neutral compounds in cometary atmospheres. II. Production rate and lifetime of OH radicals in comet Kobayashi-Berger-Milon (1975 IX),' Astron. Astrophys. 96, 52-57.

Formisano, V., Amata, E., Cattaneo, M. B., Torrente, P., Johnstone, A., Coates, A., Wilken, B., Jockers, K., Thomsen, M., Winningham, D., and Borg, H. (1988) 'Plasma flow inside comet P/Halley,' Astron. Astrophys., submitted. 
Fuselier, S. A., Shelley, E. G., Balsiger, H., Geiss, J., Goldstein, B. E., Goldstein, R., and Ip, W.-H. (1988) 'Cometary $\mathrm{H}_{2}^{+}$and solar wind $\mathrm{He}^{2+}$ dynamics across the Halley cometopause,' Geophys. Res. Lett. 15, 549-552.

Galeev, A. A. (1987) 'Encounters with comets: Discoveries and puzzles in cometary plasma physics,' Astron. Astrophys. 187, 12-20.

Galeev, A. A., Gringauz, K. I., Klimov, S. I., Remizov, A. P., Sagdeev, R. Z., Savin, S. P., Sokolov, A. Yu., Verigin, M. I., Szegoe, K., Tatrallyay, M., Grard, R., Yeroshenko, Ye. G., Mogilevsky, M. J., Riedler, W., and Schwingenschuh, K., (1987) 'Physical processes in the vicinity of the cometopause interpreted on the basis of plasma, magnetic field and plasma wave data measured on board the VEGA-2 spacecraft,' ESA SP-278, pp. 83-87.

Gammelgaard, P., and Thomson, B. (1988) ' $\mathrm{C}_{2}, \mathrm{H}_{2} \mathrm{O}^{+}$, and dust distribution in comet $\mathrm{P} / \mathrm{Halley}$ near opposition,' Astron. Astrophys. 197, 320-326.

Geiss, J. (1988) 'Composition in Halley's comet: Clues to origin and history of cometary matter,' Rev. Mod. Astron. 1, 1-27.

Goldstein, B. E., Neugebauer, M., Balsiger, H., Drake, J., Fuselier, S. A., Goldstein, R., Ip, W. -H., Rettenmund, U., Rosenbauer, H., Schwenn, R., and Shelley, E. G. (1987) 'Giotto-IMS observations of ion-flow velocities and temperatures outside the magnetic cavity of comet P/Halley,' Astron. Astrophys. 187, 174-178.

Goldstein, R., Young, D. T., Balsiger, H., Buehler, F., Goldstein, B. E., Neugebauer, M., Rosenbauer, H., Schwenn, R., and Shelley, E. G. (1987) 'Hot ions observed by the Giotto ion mass spectrometer at the comet P/Halley contact surface,' Astron. Astrophys. 187, 220-224.

Gredel, R., van Dishoeck, E. F., and Black J. H. (1989) 'Fluorescent vibration-rotation excitation of cometary $\mathrm{C}_{2}$,' Astrophys. J. 338, 1047-1070.

Gringauz, K. I., Gombosi, T. I., Remizov, A. P., Apáthy, I., Szemerey, I., Verigin, M. I., Denchikova, L. I., Dyachkov, A. V., Keppler, E., Klimenko, I. N., Richter, A. K., Somogyi, A. J., Szegö, K., Szendrö, S., Tátrallyay, M., Varga, A., and Vladimirova, G. A. (1986) 'First in situ plasma and neutral gas measurements at comet Halley,' Nature 321, 282-285.

Haser, L. (1966) 'Calcul de distribution d'intensité relative dans une tête cométaire,' Mèm. Soc. Roy. Sci., Liège, Ser. 5, 12, 233-241.

Herbst, E. (1987) 'Gas phase chemical processes in molecular clouds,' in D. J. Hollenbach and H. A. Thronson, Jr. (eds.), Interstellar Processes, D. Reidel Publ. Co., Dordrecht, pp. 611-629.

Heyl, M., Roessler, K., and Fahr, H. J. (1989) Adv. Space Sci., in press.

Huebner, W. F. (1985) 'The photochemistry of comets,' in J. S. Levine (ed.), The Photochemistry of Atmospheres: Earth, the Other Planets, and Comets, Academic Press, Orlando, pp. 437-481:

Huebner, W. F., and Boice, D. C. (1989) 'Polymers in comet comae,' in J. H. Waite, Jr., J. L. Burch, and R. L. Moore (eds.), AGU Monograph 54, pp. 453-456.

Huebner, W. F., and Giguere, P. T. (1980) 'A model of comet comae. II. Effects of solar photodissociative ionization,' Astrophys. J. 238, 753-762.

Huebner, W. F., and Keady, J. J. (1984) 'First-flight escape from spheres with $\mathrm{R}^{-2}$ density distribution,' Astron. Astrophys. 135, 177-180.

Huebner, W. F., Giguere, P. T., and Slattery, W. L. (1982) 'Photochemical processes in the inner coma', in L. L. Wilkening (ed.), Comets, University of Arizona Press, Tucson, p. 496.

Johnstone, A. D., Coates, A. J., Heath, J., Thomsen, M. F., Wilken, B., Jockers, K., Formisano, V., Amata, E., Winningham, J. D., Borg, H., and Bryant, D. A. (1987) 'Alfvénic turbulence in the solar wind flow during the approach to comet P/Halley,' Astron. Astrophys. 187, 25-32.

Kawara, K., Gregory, B., Yamamoto, T., and Shibai, H. (1988) 'Infrared spectroscopic observation of methane in comet P/Halley,' Astron. Astrophys. 207, 174-181.

Keller, H. U. (1976) 'The interpretations of ultraviolet observations of comets,' Space Sci. Rev. 18, 641-684.

Keller, H. U., Delamere, W. A., Huebner, W. F., Reitsema, H. J., Schmidt, H. U., Whipple, F. L., Wilhelm, K., Curdt, W., Kramm, R., Thomas, N., Arpigny, C., Barbieri, C., Bonnet, R. M., 
Cazes, S., Coradini, M., Cosmovici, C. B., Hughes, D. W., Jamar, C., Malaise, D., Schmidt, K., Schmidt, W. K. H., and Seige, P. (1987) 'Comet P/Halley's nucleus and its activity,' Astron. Astrophys. 187, 807-823.

Kitamura, Y. (1986) 'Axisymmetric dusty gas jet in the inner coma of a comet,' Icarus 66, 241-257.

Kitamura, Y. (1987) 'Axisymmetric dusty gas jet in the inner coma of a comet. II. The case of isolated jets,' Icarus 72, 555-567.

Kitamura, Y., Ashihara, O., and Yamamoto, T. (1985) 'A model for the hydrogen coma of a comet,' Icarus 61, 278-295.

Kömle, N. I., and Ip, W.-H. (1987) 'Anisotropic non-stationary gas flow dynamics in the coma of comet P/Halley,' Astron. Astrophys. 187, 405-410.

Körösmezey, A., and Gombosi, T. I. (1990) 'A time-dependent dusty gas dynamic model of axisymmetric cometary jets,' Icarus 84, 118-153.

Korth, A., Marconi, M. L., Mendis, D. A., Krueger, F. R., Richter, A. K., Lin, R. P., Mitchell, D. L., Anderson, K. A., Carlson, C. W., Rème, H., Sauvaud, J. A., and d'Uston, C. (1989) 'Probable detection of organic-dust-borne aromatic $\mathrm{C}_{3} \mathrm{H}_{3}^{+}$ions in the coma of comet Halley,' Nature 337, 53-55.

Krankowsky, D., Lämmerzahl, P., Herrwerth, I., Woweries, J., Eberhardt, P., Dolder, U., Herrmann, U., Schulte, W., Berthelier, J. J., Illiano, J. M., Hodges, R. R., and Hoffman, J. H. (1986) 'In situ gas and ion measurements at comet Halley,' Nature 321, 326-329.

Krishna Swamy, K. S., and O'Dell, C. R. (1981) 'Statistical equilibrium in cometary diatomic carbon. III. Triplet-singlet, Phillips, Ballik-Ramsay, and Mulliken bands,' Astrophys. J. 251, 805-808.

Lämmerzahl, P., Krankowsky, D., Hodges, R. R., Stubbemann, U., Woweries, J., Herrwerth, I., Berthelier, J. J., Illiano, J. M., Eberhardt, P., Dolder, U., Schulte, W., and Hoffman, J. H., (1987) 'Expansion velocity and temperatures of gas and ions measured in the coma of comet P/Halley,' Astron. Astrophys. 187, 169-173.

Marconi, M. L., and Mendis, D. A. (1982) 'The photochemistry and dynamics of a dusty cometary atmosphere,' Moon Planets 27, 27-47.

Magee-Sauer, K., Scherb, F., Roesler, F. L., and Harlander, J. (1989) 'Fabry-Perot observations of $\mathrm{NH}_{2}$ emission for Comet Halley,' Icarus 82, 50-60.

McDonnell, J. A. M., Pankiewicz, G. S., Birchley, P. N. W., Green, S. F., and Perry, C. H. (1990) 'The comet nucleus: Ice and dust morphological balances in a production surface of comet P/Halley,' Proceedings 20th Lunar and Planetary Sci. Conf., pp. 373-378.

Mendis, D. A., Houpis, H. L. F., and Marconi, M. L. (1984) 'The physics of comets,' in V. M. Canuto and B. G. Elmegreen (eds.), Fundamentals of Cosmic Physics, Gordon Breach Science Publ., New York, pp. 1-380.

Millis, R. L., and Schleicher, D. G. (1986) 'Rotational period of comet Halley,' Nature 324, 646-649.

Mitchell, D. L., Lin, R. P., Anderson, K. A., Carlson, C. W., Curtis, D. W., Korth, A., Richter, A. K., Rème, H., Sauvaud, J. A., d'Uston, C., and Mendis, D. A. (1986) 'Derivation of heavy (10-210 amu) ion composition and flow parameters for the Giotto PICCA instrument,' in B. Battrick, E. J. Rolfe, and R. Reinhard (eds.), 20th ESLAB Symposium on the Exploration of Halley's Comet, ESA publication SP-250, Vol. I, pp. 203-205.

Moroz, V. I., Combes, M., Bibring, J. P., Coron, N., Crovisier, J., Encrenaz, T., Crifo, J. F., Sanko, N., Grigoryev, A. V., Bockelée-Morvan, D., Gispert, R., Nikolsky, Y. V., Emerich, C., Lamarre, J. M., Rocard, F., Krasnopolsky, V. A., and Owen, T. (1987) 'Detection of parent molecules in comet P/Halley from the IKS-Vega experiment,' Astron. Astrophys. 187, 513-518.

Neubauer, F. M., Glassmeier, K. H., Pohl, M., Raeder, J., Acuna, M. H., Burlaga, L. F., Ness, N. F., Musmann, G., Mariani, F., Wallis, M. K., Ungstrup, E., and Schmidt, H. U. (1986) 'First results from the Giot to magnetometer experiment at comet Halley,' Nature 321, 352-355. 
Neugebauer, M., Lazarus, A. J., Altwegg, K., Balsiger, H., Goldstein, B. E., Goldstein, R., Neubauer, F. M., Rosenbauer, H., Schwenn, R., Shelley, E. G., and Ungstrup, E. (1987) 'The pick-up of cometary protons by the solar wind,' Astron. Astrophys. 187, 21-24.

Newburn, R. L., Jr., and Spinrad, H. (1984) 'Spectrophotometry of 17 comets. I. The emission features,' Astron. J. 89, 289-309.

O'Dell, C. R., Robinson, R. R., Krisna Swamy, K. S., McCarthy, P. J., and Spinrad, H. (1988) ${ }^{\prime} \mathrm{C}_{2}$ in comet Halley: Evidence for its being third generation and resolution of the vibrational population discrepancy,' Astrophys. J. 334, 476-488.

Rème, H., Sauvaud, J. A., d'Uston, C., Cros, A., Anderson, K. A., Carlson, C. W., Curtis, D. W., Lin, R. P., Korth, A., Richter, A. K., and Mendis, D. A. (1987) 'General features of comet P/Halley: Solar wind interaction from plasma measurements,' Astron. Astrophys. 187, 33-38.

Schleicher, D. G., and Millis, R. L. (1989) 'Revised scale lengths for cometary NH,' Astrophys. J. 339, 1107-1114.

Schloerb, F. P., Kinzel, W. M., Swade, D. A., and Irvine, W. M. (1987) 'Observations of HCN in comet P/Halley,' Astron. Astrophys. 187, 475-480.

Schmidt, H. U., and Wegmann, R. (1982) 'Plasma flow and magnetic fields in comets,' in L. L. Wilkening (ed.), Comets, University of Arizona Press, Tucson, pp. 538-560.

Schmidt, H. U., Wegmann, R., Huebner, W. F., and D. C. Boice (1988) 'Cometary gas and plasma flow with detailed chemistry,' Comp. Phys. Comm. 49, 17-59.

Tegler, S., and Wyckoff, S. (1989) ' $\mathrm{NH}_{2}$ fluorescence efficiencies and the $\mathrm{NH}_{3}$ abundance in comet Halley,' Astrophys. J. 343, 445-449.

Van Dishoeck, E. F., and Dalgarno, A. (1984) 'The dissociation of OH and OD in comets by solar radiation,' Icarus 59, 305-313.

Wegmann, R., Schmidt, H. U., Huebner, W. F., and Boice, D. C. (1987) 'Cometary MHD and chemistry,' Astron. Astophys. 187, 339-350.

Whipple, F. L. (1950) 'A comet model. I. The acceleration of comet Encke', Astrophys. J. 111, 375-394.

Wyckoff, S., Wehinger, P. A., Spinrad, H., and Belton, M. J. S. (1988) 'Abundances in comet Halley at the time of the spacecraft encounters,' Astrophys. J. 325, 927-938. 